\title{
Impact of Reaction Chamber Geometry on the Particle-Residence-Time in Flame Spray Process
}

\author{
Lizoel Buss $^{1}$ (D) . Dirceu Noriler ${ }^{2}$ (D) . Udo Fritsching ${ }^{1,3}$ (D)
}

Received: 2 December 2019 / Accepted: 10 June 2020

(c) The Author(s) 2020, corrected publication 2021

\begin{abstract}
Production of functional nanoparticles and nanoscaled powders is a key process in several recent industrial applications. In this work, the flame process in nanoparticle production in sprays is analyzed. Specific focus is on the flow behavior, the temperature distribution, and the residence-time of particles in the hot (reactive) regions in a flame spray reactor that are analyzed by numerical simulations using computational fluid dynamics techniques. The role of the co-flowing gas rate provided to the flame spray reactor and its effects on the spray behavior, flame morphology, and particle properties in an enclosed atmosphere is highlighted. The influence of different operational conditions on the reactor temperature and temperature-residence-time distribution of gas and particles is investigated. It is found that providing a reduced co-flowing gas rate to the flame spray reactor favors the recirculation of hot gas, and, consequently increases the residence-time of particles in the hightemperature regions. The numerical results of particle diameter and gas-phase temperature are compared to some existing experimental data.
\end{abstract}

Keywords Flame spray pyrolysis $\cdot$ Nanoparticle synthesis $\cdot$ Particle residence time Temperature residence time $\cdot$ Particle size control $\cdot$ Computational fluid dynamics

\section{List of Symbols}

\section{Greek Letters}

$\alpha_{j, r} \quad$ Rate exponent for species $j$ in the reaction $r$

$\beta \quad$ Agglomeration rate $\left(\mathrm{m}^{3} \mathrm{~s}^{-1}\right)$

$\beta_{r} \quad$ Temperature exponent

$\gamma \quad$ Surface tension $\left(\mathrm{J} \mathrm{m}^{-2}\right)$

$\gamma^{*} \quad$ Mass fraction of the fine structure

$\Gamma_{k} \quad$ Effective diffusivity of $k\left(\mathrm{~kg} \mathrm{~m}^{-1} \mathrm{~s}^{-1}\right)$

$\Gamma_{t} \quad$ Effective turbulent diffusivity $\left(\mathrm{m}^{-2} \mathrm{~s}^{-1}\right)$

Lizoel Buss

1.buss@iwt.uni-bremen.de

1 Chemical and Process Engineering, Leibniz Institute for Materials Engineering IWT, Bremen, Germany

2 School of Chemical Engineering, University of Campinas, Campinas, Brazil

3 Particles and Process Engineering, University of Bremen, Bremen, Germany 


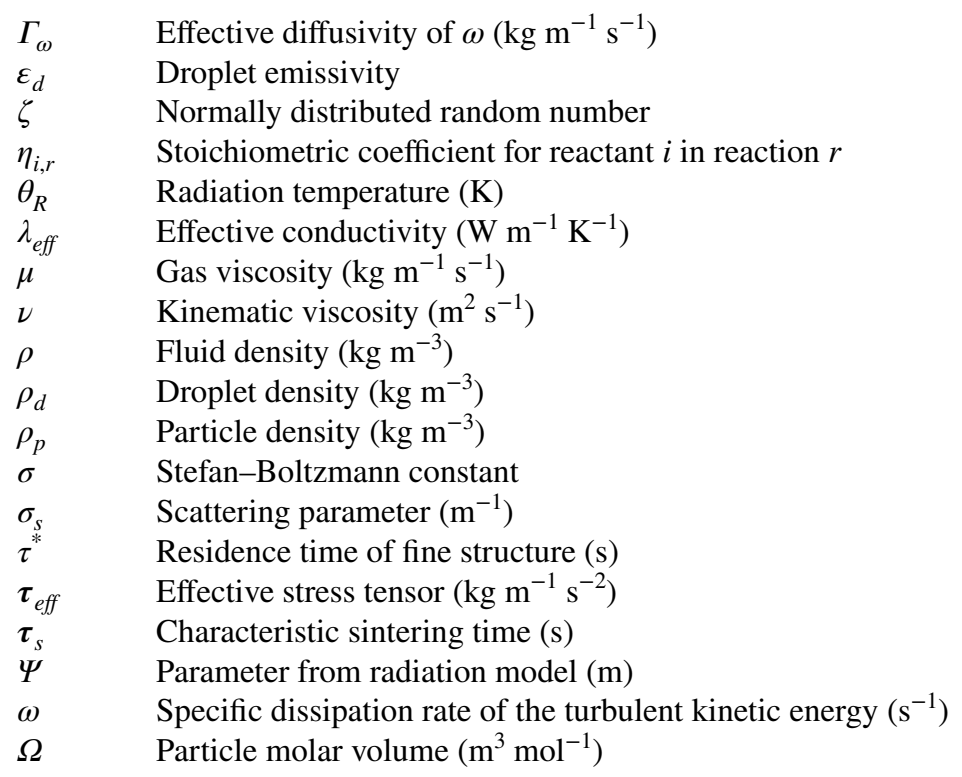

\section{Latin Letters}

a Absorption coefficient $\left(\mathrm{m}^{-1}\right)$

$a_{0} \quad$ Nuclei surface area $\left(\mathrm{m}^{2}\right)$

$a_{d} \quad$ Surface area per volume unit $\left(\mathrm{m}^{2} \mathrm{~m}^{-3}\right)$

$a_{s} \quad$ Surface area of a completely fused agglomerate $\left(\mathrm{m}^{2}\right)$

$A \quad$ Agglomerate area concentration $\left(\mathrm{m}^{2} \mathrm{~m}^{-3}\right)$

$A_{d} \quad$ Droplet surface area (m)

$A_{\text {domain }} \quad$ Area of the 2D numeral domain $\left(\mathrm{m}^{2}\right)$

$A_{r} \quad$ Pre-exponential factor

$c \quad$ Particle velocity $\left(\mathrm{m} \mathrm{s}^{-1}\right)$

$c_{p} \quad$ Heat capacity $\left(\mathrm{J} \mathrm{kg}^{-1} \mathrm{~K}^{-1}\right)$

$C_{D} \quad$ Drag coefficient

$d_{p} \quad$ Primary particle diameter (m)

$d_{v e} \quad$ Agglomerate volume equivalent diameter (m)

$D \quad$ Particle diffusion coefficient $\left(\mathrm{m}^{2} \mathrm{~s}^{-1}\right)$

$D_{b} \quad$ Grain boundary diffusion coefficient $\left(\mathrm{m}^{2} \mathrm{~s}^{-1}\right)$

$D_{f} \quad$ Agglomerate fractal dimension

$D_{i, e f f} \quad$ Effective mass diffusion coefficient for species in the mixture $\left(\mathrm{m}^{2} \mathrm{~s}^{-1}\right)$

$D_{T, i} \quad$ Thermal (Soret) diffusion coefficient $\left(\mathrm{kg} \mathrm{m}^{-1} \mathrm{~s}^{-1}\right)$

$D_{k} \quad$ Dissipation of $\mathrm{k}$ due to turbulence $\left(\mathrm{kg} \mathrm{m}^{-1} \mathrm{~s}^{-3}\right)$

$D_{\omega} \quad$ Dissipation of $\omega$ due to turbulence $\left(\mathrm{kg} \mathrm{m}^{-1} \mathrm{~s}^{-3}\right)$

$E_{r} \quad$ Activation energy of reaction $r\left(\mathrm{~J} \mathrm{k} \mathrm{mol}^{-1}\right)$

$g \quad$ Transition parameter (m)

g Gravity $\left(\mathrm{m} \mathrm{s}^{-2}\right)$

$G_{k} \quad$ Generation of turbulent kinetic energy $\left(\mathrm{kg} \mathrm{m}^{-1} \mathrm{~s}^{-3}\right)$

$G_{\omega} \quad$ Specific dissipation rate due to the mean velocity gradient $\left(\mathrm{kg} \mathrm{m}^{-1} \mathrm{~s}^{-3}\right)$

$h_{r, r x} \quad$ Enthalpy of the $r$ th reaction $\left(\mathrm{J} \mathrm{kg}^{-1}\right)$

$h_{\text {vap }} \quad$ Latent heat $\left(\mathrm{J} \mathrm{kg}^{-1}\right)$ 


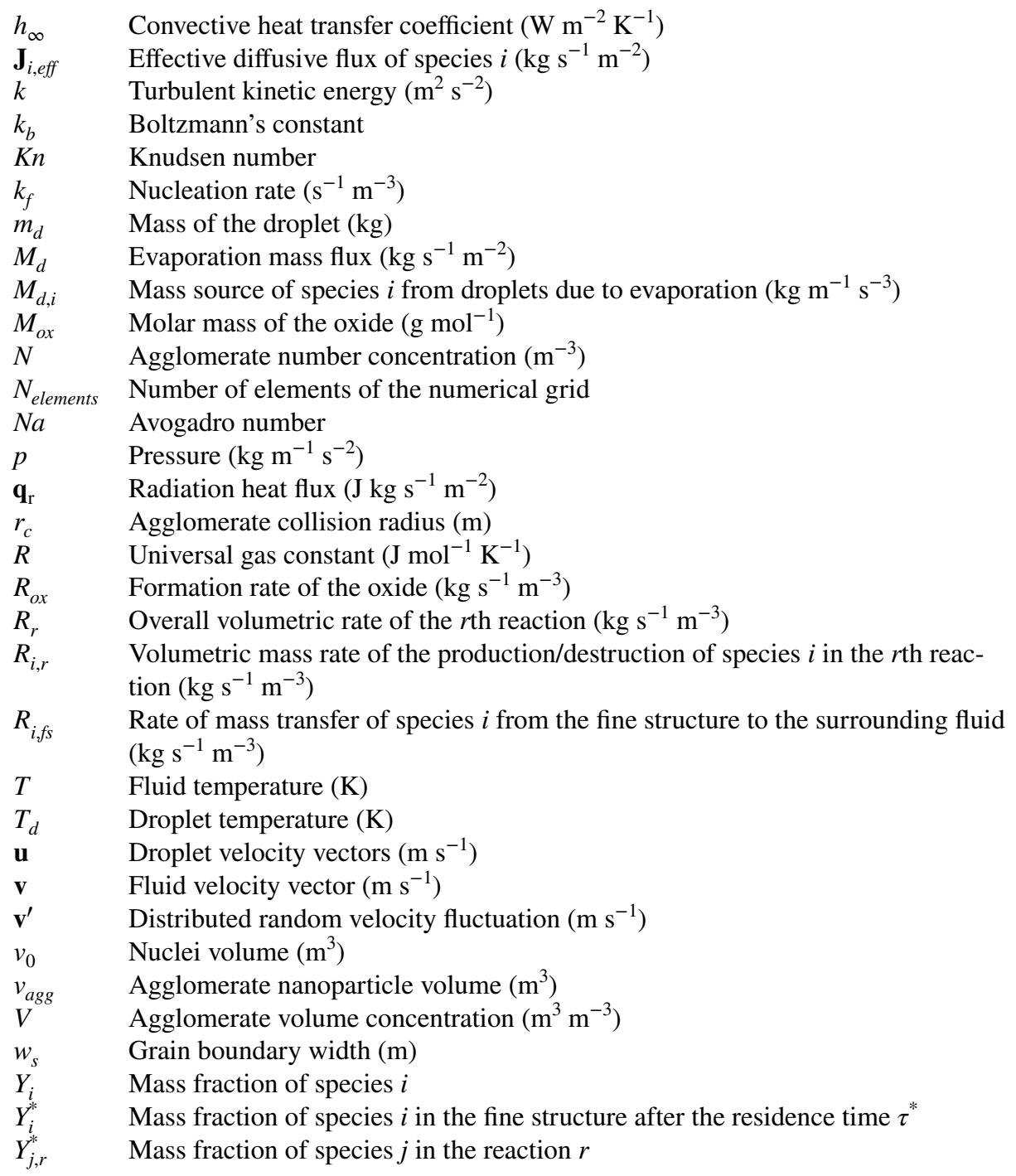

\section{Introduction}

The production and formulation of particles and powders can be found in several industrial applications. Particle production is typically performed within an enclosed environment (spray tower, mill, spray chamber, etc.). The synthesis of metal-oxide nanoparticles, which finds applications in a wide field of industries using the flame spray pyrolysis (FSP) process, plays a key role in actual technical developing areas since a broad spectrum of materials and functionalities can be produced. In the FSP process, a metal-based precursor is dissolved in an organic solvent (e.g. ethanol) which is atomized into a spray of fine droplets. These droplets may partially or even completely vaporize and the combustible vapor, in turn, ignites due to the thermal energy provided by a support-flame that surrounds 
the spray nozzle (Buss et al. 2019). The combustion reactions of the organic solvent release enough energy to crack and oxidize the precursor molecules, resulting in a supersaturated ambiance of metallic oxide vapor, which, in turn, induces nucleation followed by growth, agglomeration, and sintering of nanoparticles (Teoh et al. 2010). Some advantages of this process are the possibility of dissolving the metal-based precursor directly in the fuel/solvent and, thus, releasing it in the reaction zone, the flexibility for rapid quenching to control the particle growth (Mädler et al. 2002) and the versatility to produce metal oxide powders with high levels of purity and reasonably narrow size range (Pratsinis 2010) without any additional purification.

In order to improve the material properties and increase the production rate, variations of such process and reactor/atomizer designs have been investigated (Buss et al. 2019; Fritsching 2006; Meierhofer et al. 2014, 2017; Achelis et al. 2014; Grossmann et al. 2015; Stodt et al. 2019). Most previous studies on FSP process consider an open flame spray reactor, which has specific gas entrainment that is primarily controlled by the jet strength. With this setup, however, the control of the reaction atmosphere is complex and, depending on the required particle characteristics, might be challenging (Buss et al. 2019). By enclosing the flame spray and the FSP reactor, this task can be solved. However, depending on the quantity of co-flowing gas provided to the reactor, higher temperatures inside the reactor are observed, since the natural entrainment is suppressed and, therefore, its quenching effect is also suppressed (Buss et al. 2019). Consequently, larger nanoparticles are produced, since the growth of nanoparticles is temperature-dependent (Buss et al. 2019; Waser et al. 2013). In contrast, it has also been shown that enclosed reactors can influence the formation of the major crystal phase of particles ( $\mathrm{Li}$ et al. 2007; Kho et al. 2011; Waser et al. 2017), which is especially interesting for purposes requiring pure-phase materials (Buss et al. 2019). Providing a proper co-flowing gas rate, the reaction atmosphere inside the reactor can be better controlled which, in turn, leads to better control of particle properties (Buss et al. 2018).

The development and scale-up of FSP reactors are challenging and can be supported by computational fluid dynamics (CFD) techniques, which permit a detailed analysis of the reaction chamber geometry and operation conditions, as well as acquire several aspects of the complex phenomena occurring in the process (Buss et al. 2019). One important parameter to be considered in the synthesis of nanoparticles is the particle size, which characterizes the final product. For the vapor to particle conversion route, the growth of particles in the FSP process is controlled primarily by the agglomeration and sintering mechanisms, which depend on the local temperature and particle concentration. One way to determine how the particle characteristics/properties change with the reactor configuration and operating conditions is analyzing the residence-time of the produced particles, as introduced by previous investigations (Kho et al. 2011; Mueller et al. 2004; Gröhn et al. 2014), in different temperature zones of the reactor, since the particle size and structure are controlled by the agglomeration characteristic time, $\tau_{A}$, and sintering characteristic time, $\tau_{S}$, and, consequently, by the temperature-particle-residence-time (TPRT). If coagulation and sintering rates are equivalent, aggregates of nanoparticles (particles bonded by sinter necks) are formed (Buesser and Gröhn 2012). When the $\tau_{A}$ is much longer than the $\tau_{S}$, non-aggregated spherical-like nanoparticles are produced. If the $\tau_{A}$ is much shorter than $\tau_{S}$, weakly-bonded nanoparticles (soft agglomerates) are formed (Buesser and Gröhn 2012).

The present work analyses enclosed FSP processes and compares several operational conditions (co-flow gas rates) and reaction chamber geometries, and investigates their influence on the reactor temperature, TPRT and, consequently, their impact on the particle characteristics in the flame spray process. A Euler-Lagrange model framework composed 
by mass, momentum, energy, and chemical species conservation is applied to predict the velocity, pressure, temperature, and composition fields of the multiphase flow within the FSP reactor. To predict the particle growth, a population balance model (PBM) is coupled to the fluid dynamics model and, in addition, a model that takes into account the thermophoretic deposition of particles on the reactor walls is incorporated into the PBM as appropriate wall boundary conditions. The numerical results are analyzed and validated with the findings of previous FSP studies.

\section{Numerical Setup}

\subsection{Reaction Chamber Geometry and Numerical Domain}

The FSP reactor consists of a twin-fluid atomization nozzle positioned in the center of a metallic plate and surrounded by a support-flame. This metallic plate is surrounded by a porous plate that provides the co-flowing gas. The enclosure consists of a quartz glass tube with a thickness of $3 \mathrm{~mm}$, and a total height of $0.5 \mathrm{~m}$. The atomization nozzle described by Mädler et al. (2002) is applied. A sketch of the cylindrical FSP reactor with $0.1 \mathrm{~m}$ diameter with the main boundary conditions is presented in Fig. 1.

In this study, cylindrical enclosures with three different diameters and a conical geometry are investigated. Sketches of the numerical domains with the main boundary conditions are shown in Fig. 2. The inner diameters of the cylindrical geometry are 0.1, 0.15,

Fig. 1 Sketch of the flame spray reactor (cylindrical geometry with $0.1 \mathrm{~m}$ diameter) used for numerical studies

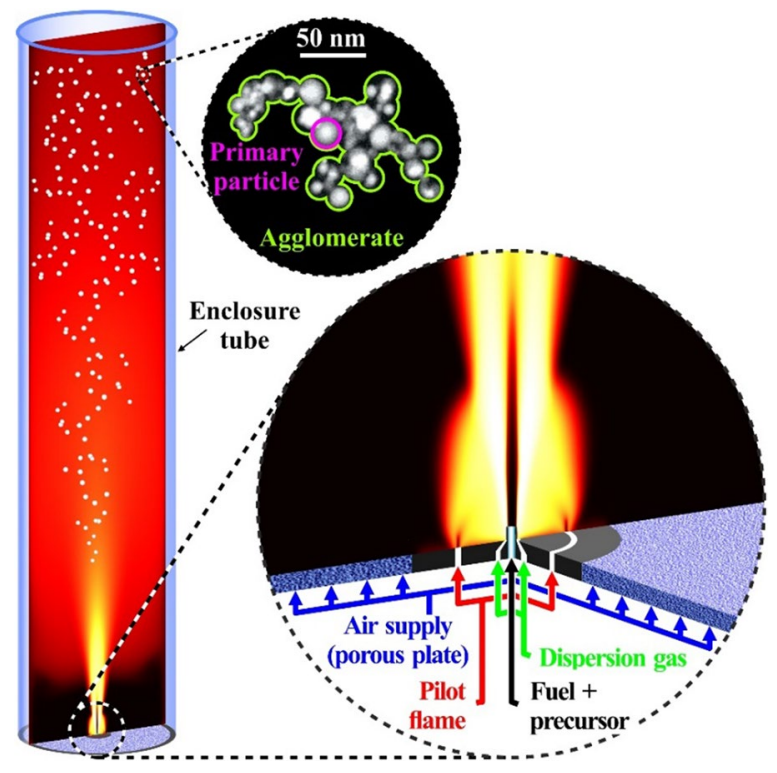




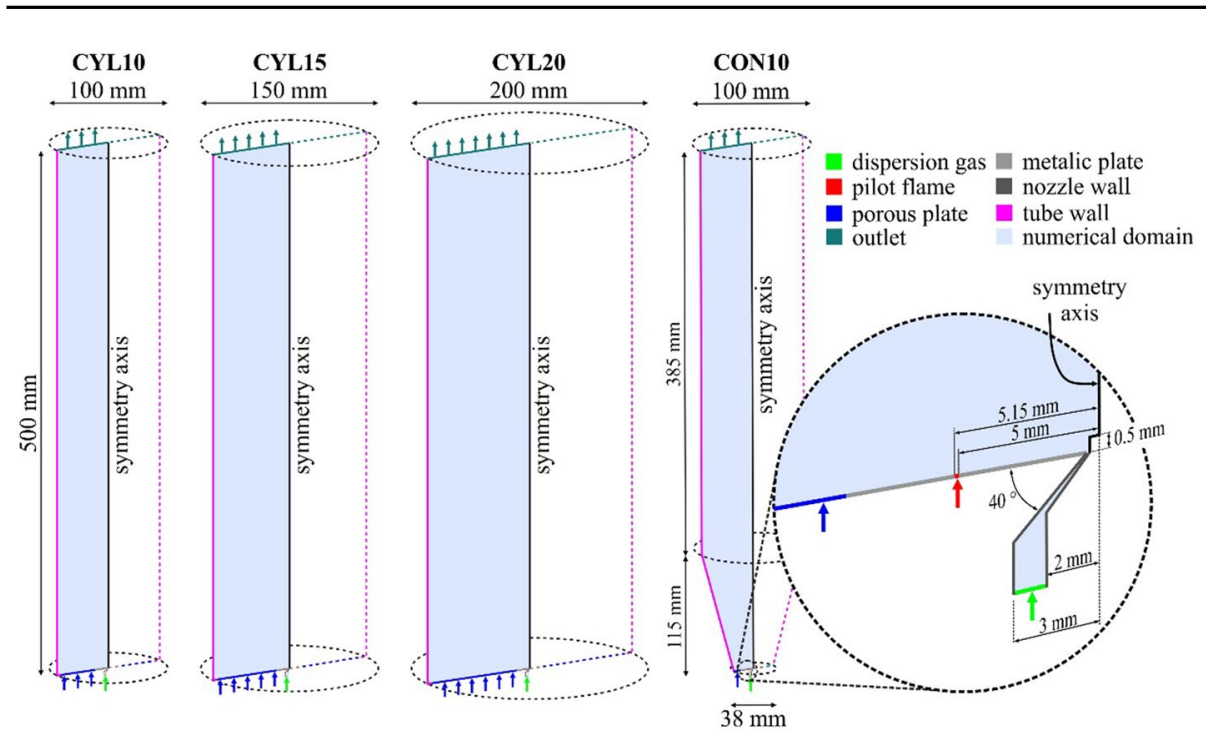

Fig. 2 Numerical domains of the FSP reactor and its main boundary conditions

and $0.2 \mathrm{~m}$ (CYL10, CYL15, and CYL20, respectively). In the conical geometry (CON10), the conical part has an inner diameter of $0.038 \mathrm{~m}$ at the bottom of the reactor. This conical part goes up to a height of $0.115 \mathrm{~m}$ and, from this position on, the inner diameter of the enclosure is $0.1 \mathrm{~m}$. The inclination angle of the conical part is $15^{\circ}$ concerning the vertical direction. In the analysis of the FSP process, numerical simulations are performed using two-dimensional (2D) axisymmetric domains. For the cylindrical enclosures, the numerical domain consists of a grid with $0.5 \mathrm{~m}$ height and 3 different widths: $0.05,0.075$, and 0.1 $\mathrm{m}$ (radius of the reactor) - considering the enclosure with $0.5 \mathrm{~m}$ of height and diameter varying between 0.1 and $0.2 \mathrm{~m}$. For the conical geometry, the numerical domain consists of a grid with $0.5 \mathrm{~m}$ height, $0.05 \mathrm{~m}$ width on the top, and $0.019 \mathrm{~m}$ width on the bottom. The computational grid is formed of quadrilateral elements, refined in the regions that present larger velocity, temperature, density, pressure, and chemical species gradients.

\subsection{Mathematical Modeling}

The applied mathematical modeling considers the gas phase as a continuum in a Eulerian framework, capturing continuity, momentum, energy, and chemical species. The liquid droplets of the precursor-solvent mixture are represented as a discrete phase in a Lagrangian approach. Two-way coupling between gas and liquid droplets is applied under steadystate and compressible flow conditions. Details on the numerical modeling procedure can be found in (Buss et al. 2019; Bianchi Neto et al. 2018). The turbulence scales are represented by the Favre-averaged-Navier-Stokes (FANS) equations, considering the eddy dissipation hypotheses. The shear-stress-transport (SST) $k-\omega$ model (Menter 1994) to calculate the turbulent viscosity. The eddy dissipation concept (EDC) model (Ertesvåg and Magnussen 2000) is employed to calculate the turbulence-chemistry interaction. The initial spray droplet size distribution (DSD) is correlated employing a Rosin-Rammler-SperlingBennet (RRSB) function to obtain the mean droplet diameter and the spread factor which 
are applied as relevant parameters for the model setup. Proper DSD's are obtained from previous studies of Bianchi Neto et al. (2018) and Buss et al. (2016). The RRSB parameters are summarized in Table 1. Turbulent droplet dispersion is predicted by a stochastic discrete random walk (DRW) model (Gosman and Ioannides 1983). The formation and growth of the solid nanoparticle are computed by a population balance model (PBM) based on the work of Kruis et al. (1993). The main equations of the mathematical modeling are presented in Tables 6 to 10 of "Appendix 1".

\subsection{Chemical Species and Properties}

Zirconium (IV) $n$-propoxide $\left(\mathrm{C}_{12} \mathrm{H}_{28} \mathrm{O}_{4} \mathrm{Zr}\right)$ is considered as the precursor to produce zirconia $\left(\mathrm{ZrO}_{2}\right)$ nanoparticles and is feed to the FSP reactor in a solution with ethanol $\left(\mathrm{C}_{2} \mathrm{H}_{5} \mathrm{OH}\right)$ and $n$-propanol $\left(\mathrm{C}_{3} \mathrm{H}_{7} \mathrm{OH}\right)$ at a concentration of $0.5 \mathrm{~mol} / \mathrm{L}$ for the liquid spray (see Table 1). The premixed pilot flame is composed of methane $\left(\mathrm{CH}_{4}\right)$ and oxygen $\left(\mathrm{O}_{2}\right)$ in a fuel-to-oxidizer equivalence ratio of 1.0. The complete list of chemical species and their thermophysical properties is presented in Tables 11 to 17 of "Appendix 2". The combustion kinetic reactions are modeled according to studies of Buss et al. (2019) and Bianchi Neto et al. (2018), using a four-step reaction mechanism for the combustion of methane, based on the kinetic rates of Jones and Lindstedt (1988) and a two-step reaction mechanism for ethanol proposed by Westbrook and Dryer (1981). The combustion mechanism of $n$-propanol is considered to be a single global reaction, as presented by Kim et al. (1998). Due to the lack of information about the zirconium (IV) $n$-propoxide, its oxidation reaction is assumed limited by mixing only, i.e., the reaction in the fine scales occurs instantaneously. The combustion kinetic mechanisms, as well as the kinetic constants adopted in the numerical simulations, are presented in Table 2.

Combustion reactions are assumed to be mixing-limited, and, therefore, the effects of turbulence on the reaction rates need to be considered. The EDC model considers the chemical reactions taking place in small turbulent scales, which are responsible for the dissipation of kinetic energy into heat, and, therefore, leading to homogeneously mixed structures of reactants.

\subsection{Particle Formation and Growth}

Formation and growth of nanoparticles are described by a monodisperse PBM based on the self-preserving particle size distribution theory for flame-made aerosols (Kruis et al. 1993), which applies the Fuchs interpolation kernel to calculate the aggregation rate. The

Table 1 RRSB parameter obtained from experiments

\begin{tabular}{ll}
\hline Parameter & Precursor-fuel mixture \\
\hline Mass flow rate, $\mathrm{kg} / \mathrm{s}$ & $7.016 \times 10^{-5}$ \\
Minimum diameter, $\mu \mathrm{m}$ & 0.90 \\
Maximum diameter, $\mu \mathrm{m}$ & 36.00 \\
Mean diameter, $\mu \mathrm{m}$ & 7.83 \\
Spread parameter & 1.48 \\
Chemical composition, g/g & $0.72\left(\mathrm{C}_{2} \mathrm{H}_{5} \mathrm{OH}\right)$ \\
& $0.08\left(n-\mathrm{C}_{3} \mathrm{H}_{7} \mathrm{OH}\right)$ \\
& $0.20\left(n-\mathrm{C}_{12} \mathrm{H}_{28} \mathrm{O}_{4} \mathrm{Zr}\right)$ \\
\hline
\end{tabular}




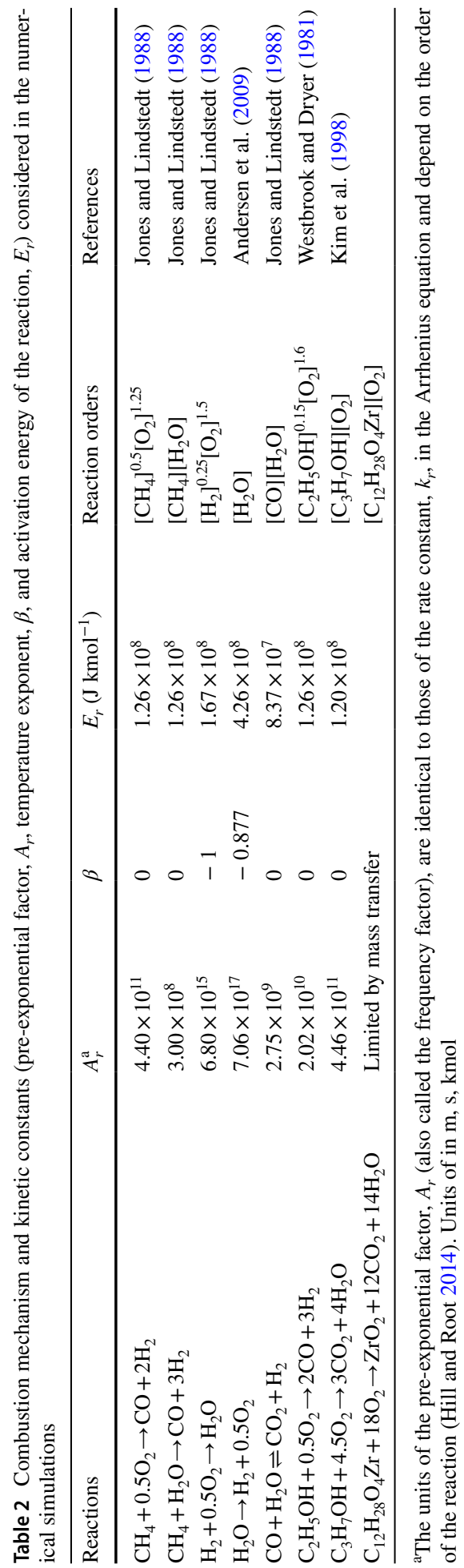


nucleation rate is defined as the formation rate of zirconia, calculated by the EDC model. The characteristic sintering time for the grain boundary diffusion (Coblenz et al. 1980) and the grain boundary diffusion coefficient (Brossmann et al. 1999) are applied to describe the sintering kinetics of zirconia. Deposition of nanoparticles on reactor walls may occur due to several mechanisms including impaction, interception, field forces (centrifugal, electrostatic, thermophoretic, and gravitational) (Talbot et al. 1980), and Brownian diffusion (Mädler et al. 2006). In the FSP process, however, the particle deposition due to impaction and interception can be neglected since the Stokes number $(\ll 1)$ is a range significantly smaller than the critical Stokes number. Electrical and centrifugal forces are neglected since no direct electrical or centrifugal fields are utilized. Gravitational effects are neglected because the settling velocity of particles is insignificant $\left(\sim 5 \times 10^{-9} \mathrm{~m} / \mathrm{s}\right)$. Brownian diffusion was determined (Brockmann 2011) and is found to be negligible, as has also been observed in the literature (Romay et al. 1998). The deposition of nanoparticles on the reactor walls is considered, therefore, to occur mainly due to the thermophoretic forces. In this contribution, the particle deposition is described by a deposition efficiency model based on previous studies (Talbot et al. 1980; Romay et al. 1998; Batchelor and Shen 1985) and takes into account the thermophoretic velocity, and, for this, the temperature gradient between the gas and reactor walls is considered.

\subsection{Numerical Methodology}

The partial differential equations (PDE) of the mathematical model are computed utilizing the finite-volume method (FVM). A pressure-based and coupled solver is utilized, under steady-state conditions and second-order spatial discretization. The in situ adaptative tabulation (ISAT) algorithm is applied to integrate the kinetic of the fine-scales. The convergence solution is achieved when all normalized residuals of the flow variables decreased by at least three orders of magnitude and variable values remained stable. The ANSYS Fluent v.14.0 code is utilized in all simulations.

Regarding the mesh quality, a grid independence study is performed using the grid convergence index (GCI) method presented by Celik et al. (2008). For each geometry, three different structured mesh schemes were evaluated with refinement ratios of $\sim 1.40$, and $\sim 1.32$ between the meshes. The co-flowing gas rate of $400 \mathrm{~L} / \mathrm{min}$ is applied in the grid analysis of conical and cylindrical with a radius of $50 \mathrm{~mm}$ geometries (CON10 and CYL10), while the co-flowing gas rate of $1000 \mathrm{~L} / \mathrm{min}$ is used into evaluate the other two cylindrical geometries (CYL15 and CYL20). Two global variables, flame height and primary particle diameter at the end of the domain, are considered to estimate the discretization error. According to Table 3, the estimated error, related to the selected meshes, is lower than $0.4 \%$.

To ensure the grid refinement is sufficient, the solution must be in an asymptotic range, i.e., the global variables should converge to a single value with the grid refinement. The convergence of the global variables according to grid refinement is shown in Fig. 3. Additionally, the orthogonality and the aspect ratio of the cells are evaluated, presenting values of $>0.95$ and $>0.5$, respectively, for over $97 \%$ of the elements.

\subsection{Operational and Boundary Conditions}

The liquid precursor-fuel mixture (zirconium (IV) n-propoxide, $n$-propanol, and ethanol) is injected at a constant mass flow of $5 \mathrm{~mL} / \mathrm{min}$ and atomized by $5 \mathrm{~L} / \mathrm{min}$ pure 


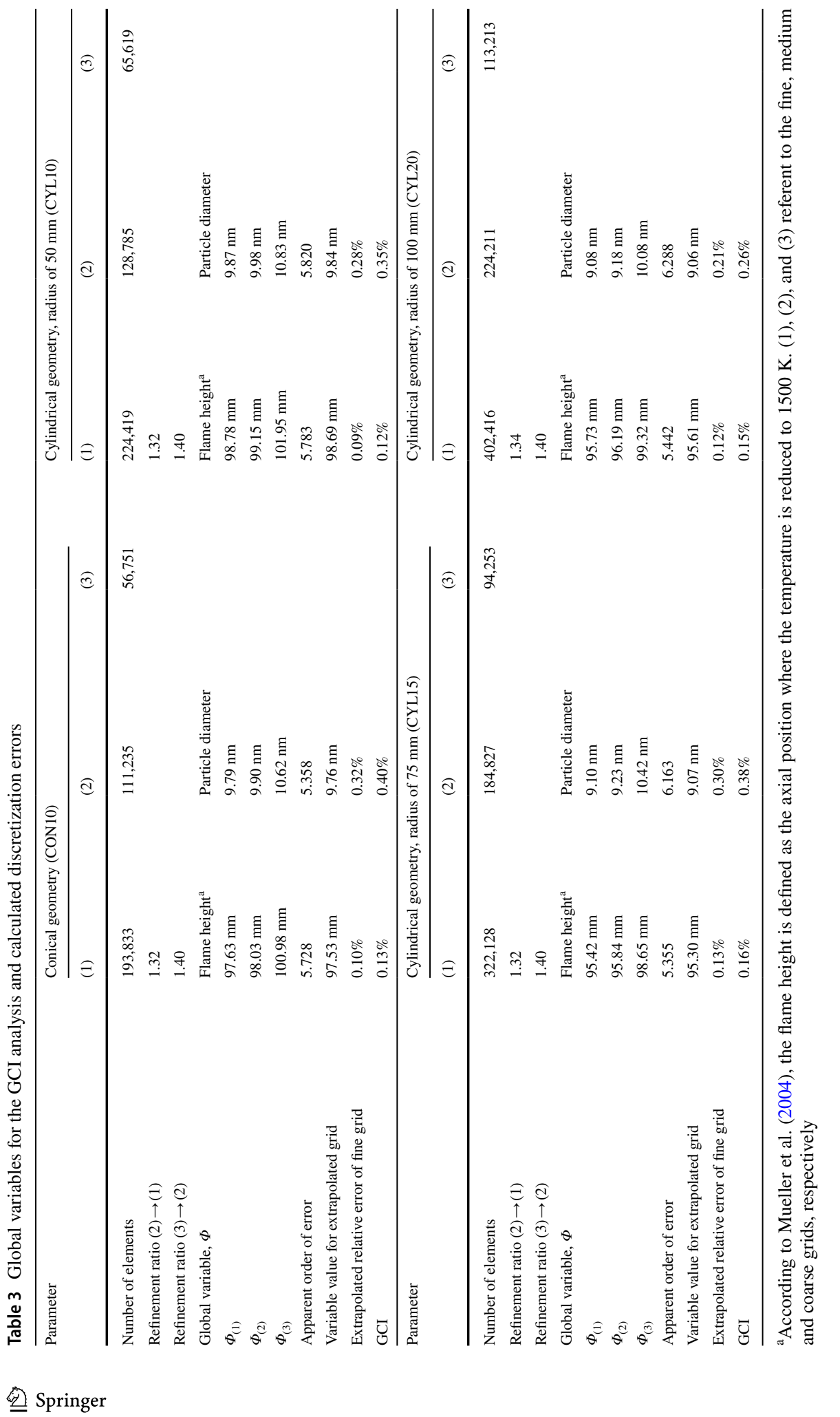




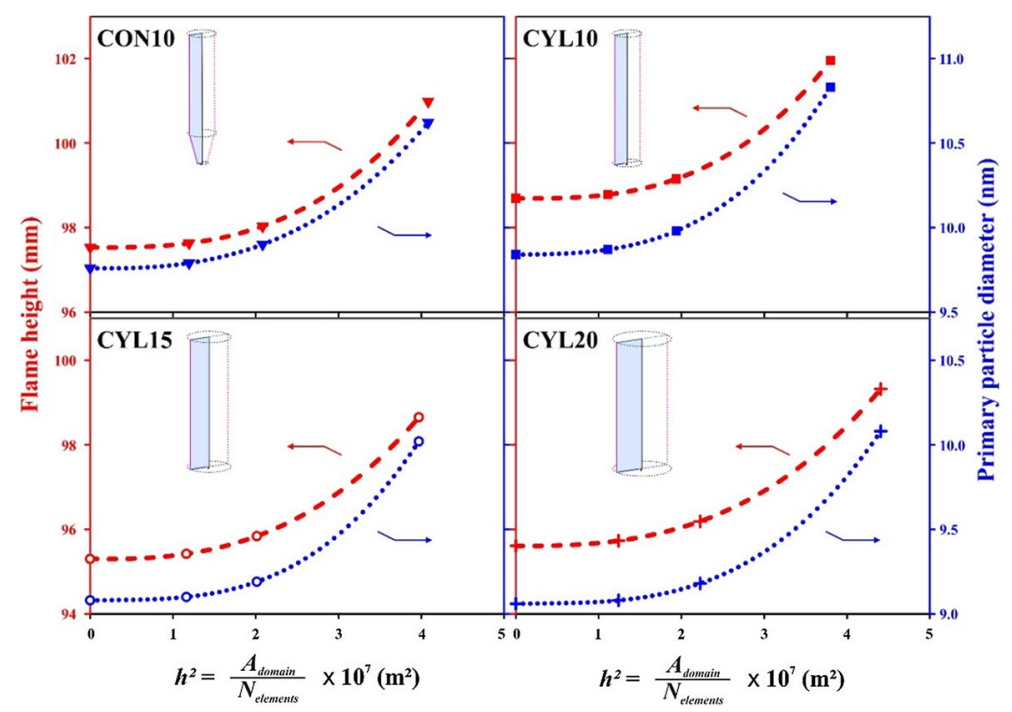

Fig. 3 Qualitative representation of the grid independence study; the flame height is represented by red lines and symbols while the primary particle diameter is denoted by blue lines and symbols

oxygen. These operational conditions provide an initial precursor-oxidizer equivalence ratio of 1.15 and, therefore, a fuel-rich flame. The nozzle gap for the dispersion gas is adjusted to result in a constant pressure drop of $1.5 \times 10^{5} \mathrm{~Pa}$. The pilot flame $(1.6$ and $3.2 \mathrm{~L} / \mathrm{min}$ of methane and oxygen, respectively) is supplied by an annular gap surrounding the spray nozzle.

Three different co-flow rates of compressed air (1000, 400, and $100 \mathrm{~L} / \mathrm{min})$ are provided to the reaction chamber (cylindrical and conical geometries) through the porous sinter metal plate surrounding the nozzle. The flow rate of $400 \mathrm{~L} / \mathrm{min}$ is obtained from the calculations of gas entrainment in the open reactor and provides a similar quantity of gas as the entrained gas in the open configuration (Buss et al. 2019). Additionally, the variation of reaction chamber diameter $(0.1,0.15$, and $0.2 \mathrm{~m})$ of the cylindrical geometry is evaluated by applying the co-flow rate of $1000 \mathrm{~L} / \mathrm{min}\left(2.126 \times 10^{-2} \mathrm{~kg} / \mathrm{s}\right)$. An overview of the different cases evaluated in this study is presented in Table 4.

The boundary conditions (Table 5) are fixed as a mass flow for oxidant, pilot flame inlet, and co-flow gas; adiabatic and impermeable wall for the nozzle and metallic plate walls; and pressure boundary (fixed static pressure and zero gradient for the remaining variables) for the top limit. Regarding the reactor walls, heat transfer through the enclosure must be considered since overestimation in the temperature field is expected when the reactor walls are adjusted to adiabatic conditions (Meierhofer et al. 2016). The mathematical description of the boundary conditions is presented in Table 9 of "Appendix 1".

Droplet breakup is not considered in the CFD simulations. The liquid phase is injected as droplets from a virtual cone surface with a base diameter of $0.72 \mathrm{~mm}$ and a height of $1.5 \mathrm{~mm}$. This injection surface describes qualitatively the outer region of the atomization zone, above the capillary tube. The initial droplet velocity is calculated based on the mass flow rate through the capillary and the initial diameter of droplets is taken from DSD (see Table 1). 
Table 4 Reaction chamber geometries and co-flow gas rates of the investigated cases

\begin{tabular}{llll}
\hline Case & Geometry & Inner diameter & Co-flowing gas rate \\
\hline CON10CF100 & Conical & $0.10 \mathrm{~m}$ & $100 \mathrm{~L} / \mathrm{min}\left(2.126 \times 10^{-3} \mathrm{~kg} / \mathrm{s}\right)$ \\
CON10CF400 & Conical & $0.10 \mathrm{~m}$ & $400 \mathrm{~L} / \mathrm{min}\left(8.504 \times 10^{-3} \mathrm{~kg} / \mathrm{s}\right)$ \\
CON10CF1000 & Conical & $0.10 \mathrm{~m}$ & $1000 \mathrm{~L} / \mathrm{min}\left(2.126 \times 10^{-2} \mathrm{~kg} / \mathrm{s}\right)$ \\
CYL10CF100 & Cylindrical & $0.10 \mathrm{~m}$ & $100 \mathrm{~L} / \mathrm{min}\left(2.126 \times 10^{-3} \mathrm{~kg} / \mathrm{s}\right)$ \\
CYL10CF400 & Cylindrical & $0.10 \mathrm{~m}$ & $400 \mathrm{~L} / \mathrm{min}\left(8.504 \times 10^{-3} \mathrm{~kg} / \mathrm{s}\right)$ \\
CYL10CF1000 & Cylindrical & $0.10 \mathrm{~m}$ & $1000 \mathrm{~L} / \mathrm{min}\left(2.126 \times 10^{-2} \mathrm{~kg} / \mathrm{s}\right)$ \\
CYL15CF1000 & Cylindrical & $0.15 \mathrm{~m}$ & $1000 \mathrm{~L} / \mathrm{min}\left(2.126 \times 10^{-2} \mathrm{~kg} / \mathrm{s}\right)$ \\
CYL20CF1000 & Cylindrical & $0.20 \mathrm{~m}$ & $1000 \mathrm{~L} / \mathrm{min}\left(2.126 \times 10^{-2} \mathrm{~kg} / \mathrm{s}\right)$ \\
\hline
\end{tabular}

Table 5 Boundary conditions adopted in the numerical simulations

\begin{tabular}{llll}
\hline Boundary name & Type & Value & Chemical composition, g/g \\
\hline Dispersion gas & Mass-flow-inlet & $1.19057 \times 10^{-4} \mathrm{~kg} / \mathrm{s}(5 \mathrm{~L} / \mathrm{min})$ & $1\left(\mathrm{O}_{2}\right)$ \\
Metallic plate & Wall & No-slip/adiabatic & - \\
Nozzle walls & Wall & No-slip/adiabatic & - \\
Outlet & Pressure-outlet & $0 \mathrm{~Pa}$ & $0.77\left(\mathrm{~N}_{2}\right) / 0.23\left(\mathrm{O}_{2}\right)$ \\
Pilot flame & Mass-flow-inlet & $9.4053 \times 10^{-5} \mathrm{~kg} / \mathrm{s}(4.7 \mathrm{~L} / \mathrm{min})$ & $0.19\left(\mathrm{CH}_{4}\right) / 0.81\left(\mathrm{O}_{2}\right)$ \\
Porous plate & Mass-flow-inlet & $2.126 \times 10^{-3} \mathrm{~kg} / \mathrm{s}(100 \mathrm{~L} / \mathrm{min})$ & $0.77\left(\mathrm{~N}_{2}\right) / 0.23\left(\mathrm{O}_{2}\right)$ \\
& & $8.504 \times 10^{-3} \mathrm{~kg} / \mathrm{s}(400 \mathrm{~L} / \mathrm{min})$ & \\
& & $2.126 \times 10^{-2} \mathrm{~kg} / \mathrm{s}(1000 \mathrm{~L} / \mathrm{min})$ & \\
Reactor walls & Wall & No-slip/heat transfer & - \\
\hline
\end{tabular}

\section{Results and Discussion}

The effects of different geometric configurations of the reaction chamber and operational conditions on the particle characteristics, namely primary particle diameter and agglomerate size, are analyzed by correlating the velocity and temperature of the gas and particles with the temperature-particle-residence-time, TPRT. To validate the mathematical model, a comparison with previous studies is performed in terms of gas temperature (Buss et al. 2019; Bianchi Neto et al. 2018) and primary particle diameter (Buss et al. 2019). These comparisons are presented in the next sections.

\subsection{Gas Velocity and Recirculation}

Results of numerical simulation regarding the velocity fields of the gas phase with different co-flow rates and reaction chamber geometries are shown in Fig. 4. The flow behavior is represented by the streamlines and the flow orientation is indicated by arrowheads. The recirculation mass flow ratio of the gas phase, which is the ratio between the fluid mass flow rate with negative/downward-oriented velocity, $\dot{m}_{r}$, and the initial mass flow rate, $\dot{m}_{0}$, of dispersion gas and liquid droplets exiting the nozzle, is presented as a function of the axial distance from the nozzle.

To understand the recirculation in confined jets or flame sprays, firstly is necessary to comprehend the role of entrainment. A fluid injected from a nozzle into a stagnant 
Fig. 4 Simulated velocity fields and flow patterns (streamlines and arrowheads) of enclosed FSP reactor with different co-flow rates and reaction chamber geometries, and relative recirculation mass flow ratio as a function of the height above the burner, HAB

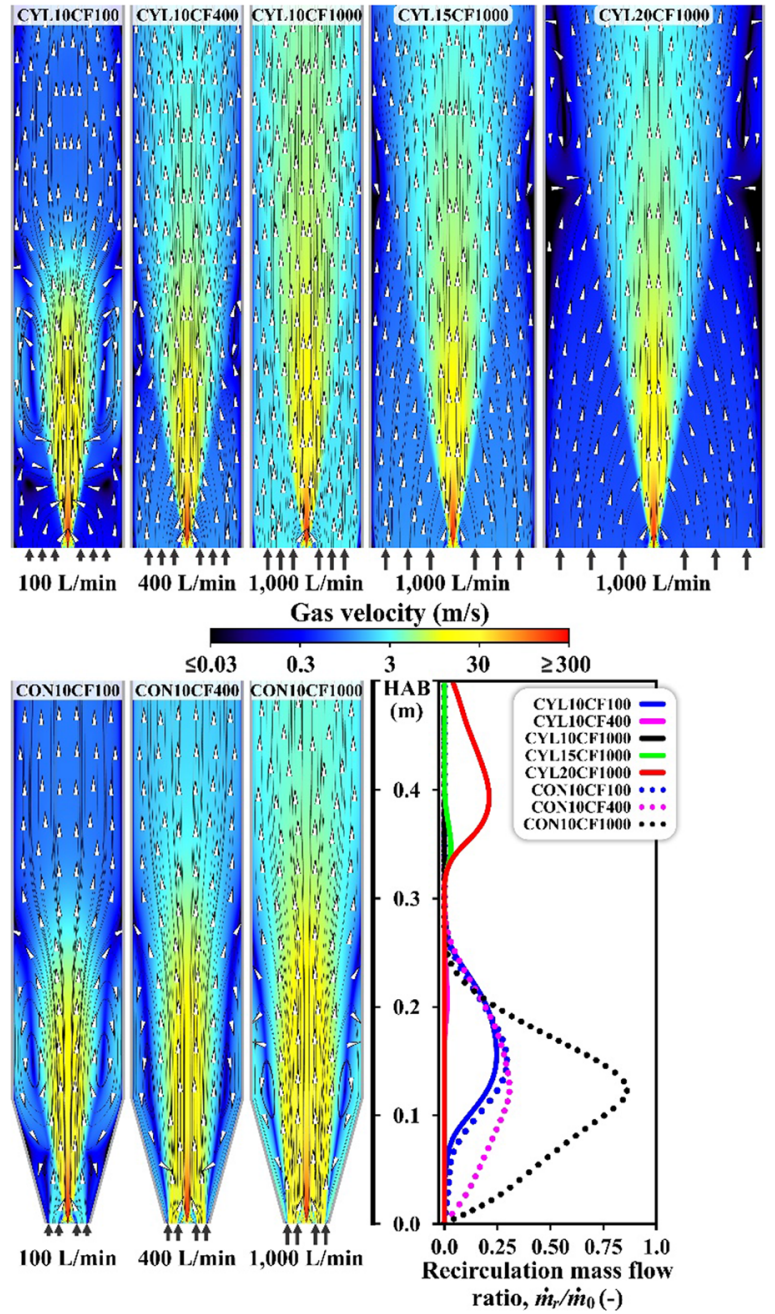

atmosphere at uniform pressure develops a free jet that spreads in this environment (Ricou and Spalding 1961). Due to the velocity gradient between the jet and the ambient, shear stress is produced in the boundary layer of the jet. The shear stress causes the formation of turbulent eddies which, in turn, increase the entrainment of the surrounding fluid into the jet flow. The total mass flow in the jet increases in the downstream direction and more surrounding fluid is drawn into the jet (Ricou and Spalding 1961; Oldenhof et al. 2011). In confined jets, the amount of surrounding fluid available to be drawn into the jet is limited by the co-flow rate. Physically, the high excess difference momentum between jet and co-flow causes the formation of recirculation zones (Ricou and Spalding 1961). In other words, if the co-flow momentum is large enough, some momentum loss of the jet occurs due to interactions between the jet and the co-flow. Any residual momentum from the jet is dissipated completely at chamber walls, and no recirculation is observed. In contrast, if the co-flow momentum is very small compared to the jet momentum, the jet momentum will not be completely dissipated, and vortex formation is detected. 
Supplying $400 \mathrm{~L} / \mathrm{min}\left(8.504 \times 10^{-3} \mathrm{~kg} / \mathrm{s}\right)$ of co-flowing gas to the cylindrical reaction chamber (CYL10CF400), almost no recirculation is observed, indicating that an adequate amount of co-flow gas satisfies the entrainment requirement of the spray flame. Providing $1000 \mathrm{~L} / \mathrm{min}\left(2.126 \times 10^{-2} \mathrm{~kg} / \mathrm{s}\right)$ of co-flowing gas a narrow jet cone angle is observed. In contrast, decreasing the co-flow rate (CYL10CF100) or increasing the reactor diameter (CYL15CF1000 and CYL20CF1000), strong vortex and recirculation zones are formed, which are usually observed in confined jets with reduced co-flow (Waser et al. 2017; Curtet 1958; Magnussen 1973). A maximum gas recirculation mass flow ratio of $23 \%$ is observed for the cases CYL10CF100 and CYL20CF1000, with 0.1 and $0.2 \mathrm{~m}$ reactor diameter, and co-flow rates of 100 and $1000 \mathrm{~L} / \mathrm{min}$, respectively. Although the maximum recirculation mass flow ratio is similar for these cases, for the last one (CYL20CF1000) the recirculation region is formed further downstream inside the reactor, since the axial position of maximum recirculation is directly associated to the enclosure diameter and the amount of co-flowing gas provided to the reactor (Curtet 1958; Magnussen 1973).

Analyzing the cases with the conical part on the bottom of the reactor enclosure (CON10CF100, CON10CF400, and CON10CF1000), opposite effects are observed in the flow behavior: the lager is the co-flowing rate provided, the stronger/larger is the recirculation vortex formation. There are two relevant aspects associated with this flow behavior. First, providing $100 \mathrm{~L} / \mathrm{min}$ co-flowing gas does not satisfy the amount of gas necessary to achieve the required entrainment of the spray flame, leading to the formation of recirculation zones (this behavior is also observed in cylindrical geometry). Second, reducing the diameter of the bottom of the reactor and increasing the co-flowing gas rate $(\geq 400 \mathrm{~L} / \mathrm{min})$, the velocity of the co-flowing gas increases, and consequently enhance the momentum generated by such flows, leading to vortex formation. The conical geometry with a co-flowing gas rate of $1000 \mathrm{~L} / \mathrm{min}(\mathrm{CN} 10 \mathrm{CF} 1000)$ presents the highest recirculation ratio ( 90\%).

\subsection{Temperature}

Proper temperature prediction and representation of the flame are crucial for simulations of the FSP process since the flame provides the thermal energy for the sintering and agglomeration of particles.

Figure 5 presents the temperature fields of the FSP reactor. For the cases with co-flowing gas rate $\geq 400 \mathrm{~L} / \mathrm{min}$, the temperature inside the reactor is quite similar. In contrast, decreasing the provided co-flow rate distinctly increases the gas temperature inside the reactor, not only due to lower quenching gas provided but also due to the recirculation of hot gases coming from the spray combustion. The lower the co-flow rate, the stronger the vortex formation, leading, in turn, to higher temperature fields in the downstream of the reactor.

Although the relative mass recirculation ratio of the conical geometry with co-flowing gas rate $\geq 400 \mathrm{~L} / \mathrm{min}$ is larger in comparison to the other analyzed cases (shown in Fig. 4), the temperature inside of the reaction chamber is similar to the cases with cylindrical geometries with the same operating conditions, mainly due to the amount of cold gas provided as co-flow, which quenches the ambient inside the chamber.

To validate the thermal behavior of the FSP process, numerical results are compared to experimental data (Buss et al. 2019; Bianchi Neto et al. 2018) as shown in Fig. 6. It depicts the local temperature obtained on the centerline of the FSP reactor. As the co-flowing gas rate of $400 \mathrm{~L} / \mathrm{min}$ is derived from the calculations of air entrainment of the open FSP configuration (Buss et al. 2019), and for both configurations (open and enclosed with 


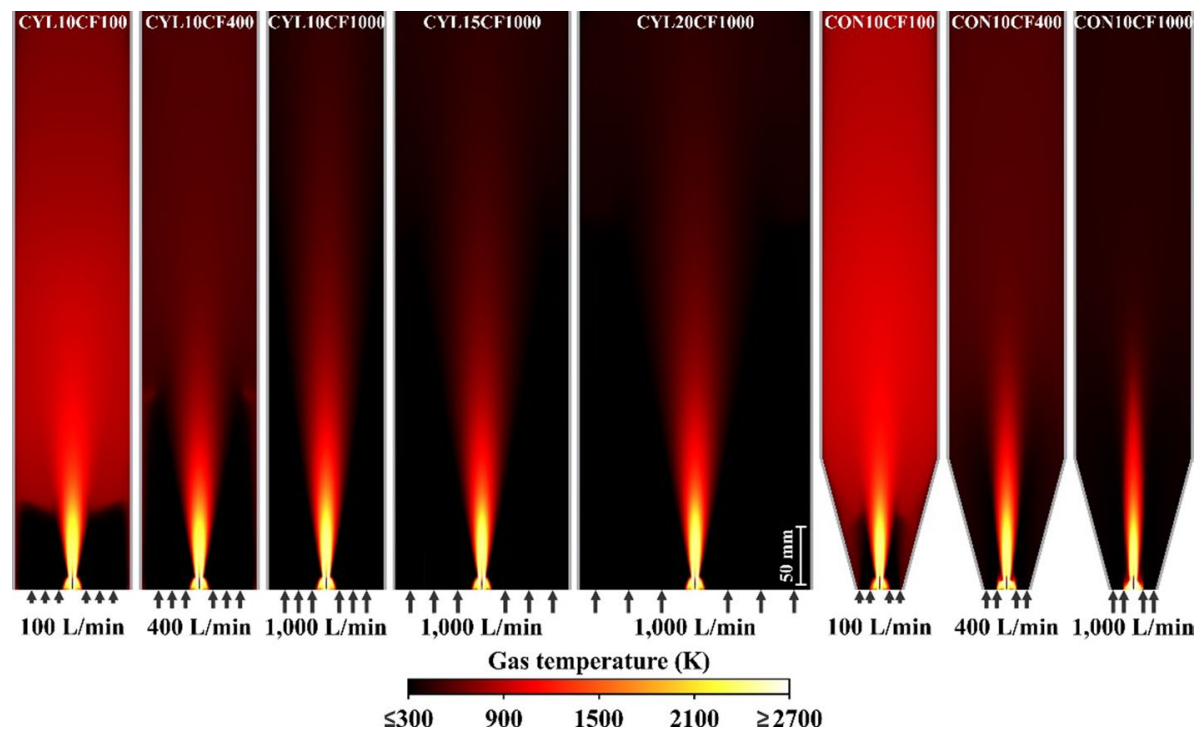

Fig. 5 Simulated temperature fields of the FSP reactor with different reaction chamber geometries and coflow rates

$400 \mathrm{~L} / \mathrm{min}$ co-flowing gas rate) the flow behavior inside the spray flame is quite similar, experimental data from the open configuration (Bianchi Neto et al. 2018) is also utilized in this analysis. The region very close to the nozzle is mainly influenced by the pilot flame combustion and, therefore, the temperature at the centerline is still lower due to dispersion gas and liquid phase temperatures. The subsequent region (up to $\mathrm{HAB} \sim 0.05 \mathrm{~m}$ ) is dominated by the precursor/fuel vaporization and combustion and the temperature rapidly rises. At $\mathrm{HAB} \sim 0.08 \mathrm{~m}$, most of the methane is already consumed but some thermal energy is still generated by the combustion of the fuel-precursor mixture. In the further downstream $(\mathrm{HAB} \geq \sim 0.1 \mathrm{~m})$, the combustion gases are quenched and the temperature profiles depend on the amount of co-flowing gas provided and, therefore, just in this region the effects of co-flow rate variations become evident. For the cases with a co-flowing gas rate of $100 \mathrm{~L} /$ min, the temperature is higher when compared to cases with co-flowing gas rates $\geq 400 \mathrm{~L} /$ min, not only in the center of the flame (Fig. 6) but also in positions near to the walls of the chamber (Fig. 5).

\subsection{Particle Formation}

The different operating conditions yield modifications of the flame spray behavior. How these modifications impact on the resulting products is investigated. To analyze the particle evolution in the FSP process, the PBM is implemented. The variables obtained by the PBM solution are the fields of surface area $\left(A_{\text {agg }}\right)$ and the volume $\left(V_{\text {agg }}\right)$ of the particle agglomerates. These variables, however, are not ideal to characterize the FSP process. A more relevant variable is the primary particle diameter, which is defined as $d_{p}=6 V_{a g g} / A_{a g g}$ (Kruis et al. 1993). To evaluate the agglomerate evolution, the agglomerate volume equivalent diameter, $d_{v e}$, is chosen. The agglomerate volume equivalent 
Fig. 6 Temperature profile of the gas phase for different FSP reactor diameters and different co-flow rates at the centerline. Experimental data from Buss et al. (2019) and Bianchi Neto et al. (2018); *Results from an open FSP reactor (without enclosure)

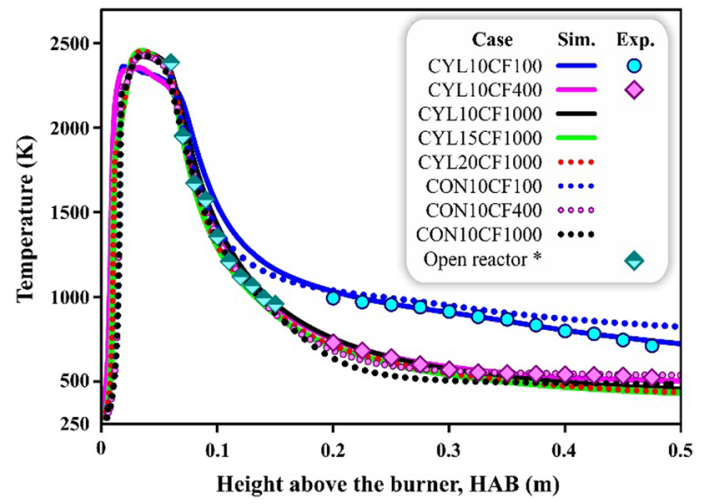

diameter is defined as the volume of a sphere with the same volume as a particle with an irregular shape (Pettibone et al. 2008) and is expressed as $d_{v e}=\left(6 V_{a g g} / \pi\right)^{1 / 3}$.

The evolution of $d_{p}$ and $d_{v e}$, according to different operating conditions and reaction chamber geometries, as a function of HAB is shown in Fig. 7. Particle nucleation starts in the early stages of the reaction chamber. As the nanostructures exit the hightemperature region $(\mathrm{T} \sim 1000 \mathrm{~K})$, the growth rate reduces until their size stabilizes at $\mathrm{HAB} \sim 0.15 \mathrm{~m}$ for the cases with co-flow rate $\geq 400 \mathrm{~L} / \mathrm{min}$, and $\mathrm{HAB} \sim 0.25 \mathrm{~m}$ for the cases with a co-flow rate of $100 \mathrm{~L} / \mathrm{min}$. The particles continue to agglomerate leading to larger clusters formation, however, as there is not enough energy for sintering, the growth of primary particles stops.

In contrast to the primary particles, the agglomerate size increases almost linearly throughout the entire reaction chamber. According to Gröhn et al. (2014), the aggregation or hard agglomeration (particles bounded together by sinter necks) ends and the soft agglomeration begins at $\sim 900 \mathrm{~K}$, and in this way, it can be expected that not only the primary particle produced by the lower co-flow rate configurations is larger, but also the degree of aggregation (hard agglomeration of particles) is higher. The correlation between the primary particle size and reactor temperature becomes evident in this investigation. For the CYL10CF100 and CON10CF100 cases, the temperature profile reaches values of $900 \mathrm{~K}$ at $\mathrm{HAB} \sim 0.27 \mathrm{~m}$ (Fig. 6) and the growth of primary particles starts to attenuate downstream of that position (Fig. 7).

Another interesting point is to investigate the particle losses to the reaction chamber walls due to the deposition processes. Changing the geometry (cylindrical to conical), an increase between 2 and $4 \%$ in the deposition of particles on the chamber walls is observed.

\subsection{Particle Recirculation and Particle-Temperature-Residence-Time}

Figure 8 presents the trajectories of formed nanoparticles, and the particles following the gas flow pattern accordingly. For the cases CYL10CF100, CYL10CF400, CYL20CF1000, and CON10CF(all), particle recirculation in different axial positions inside the FSP reactor is observed. The cases CYL10CF100 and CON10CF100 present strong particle recirculation, which starts in the hot temperature region of the reactor. On the other hand, in the cases CYL20CF1000, CON10CF400, and CON10CF1000 the gas temperature, where the recirculation region starts, is $\sim 500 \mathrm{~K}$ only, resulting in 


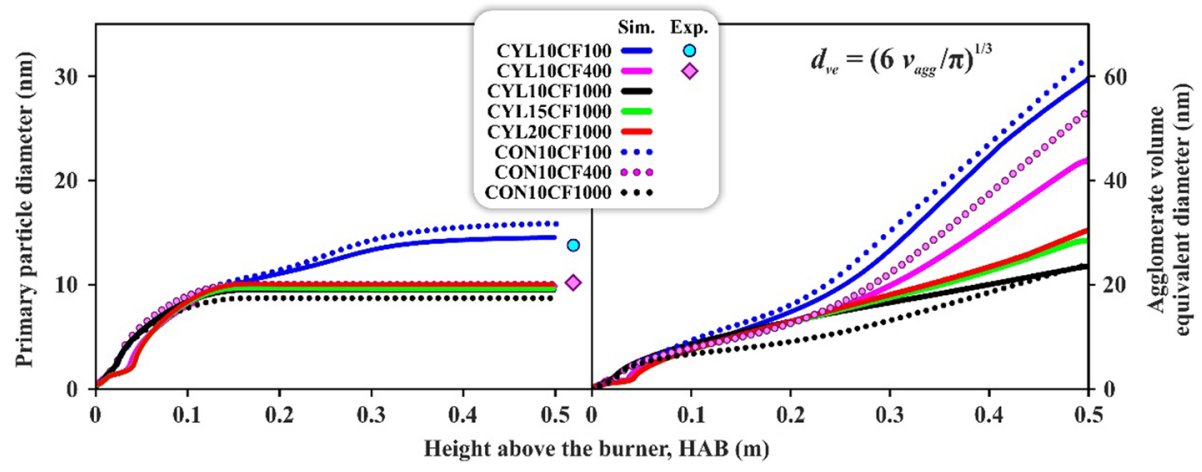

Fig. 7 Primary particle size (left) and agglomerate volume equivalent diameter (right) resulting from different operating conditions and reaction chamber geometries of the FSP process. Experimental data from Buss et al. (2019)

primary particles with the same size range as that observed in the cases CYL10C400, CYL10C1000, and CYL15C1000 (Fig. 7).

Figure 9 depicts the TPRT in different temperature zones inside the FSP reactor. In the cases with the lower co-flow rate (CYL10CF100 and CON10CF100), the TPRT inside the flame or in the hot regions is larger as in the cases with co-flow rate $\geq 400$ $\mathrm{L} / \mathrm{min}$, which leads to the formation of larger nanoparticles, as observed in Fig. 7. The TPRT in the reactor has a maximum of $\sim 0.11 \mathrm{~s}$ for the CYL10CF400 case at just 500 $\mathrm{K}$ while for CYL10CF100 and CON10CF100 cases, the maximal TPRT is $\sim 0.3 \mathrm{~s}$ (at $750 \mathrm{~K}$ ). For temperature values higher than $650 \mathrm{~K}$, the TPRT of the cases with co-flow rate $\geq 400 \mathrm{~L} / \mathrm{min}$ present quite similar results. Analyzing the region with a temperature of $1000 \mathrm{~K}$, the TPRT is $\sim 0.003 \mathrm{~s}$ cases with co-flow rates $\geq 400 \mathrm{~L} / \mathrm{min}$.
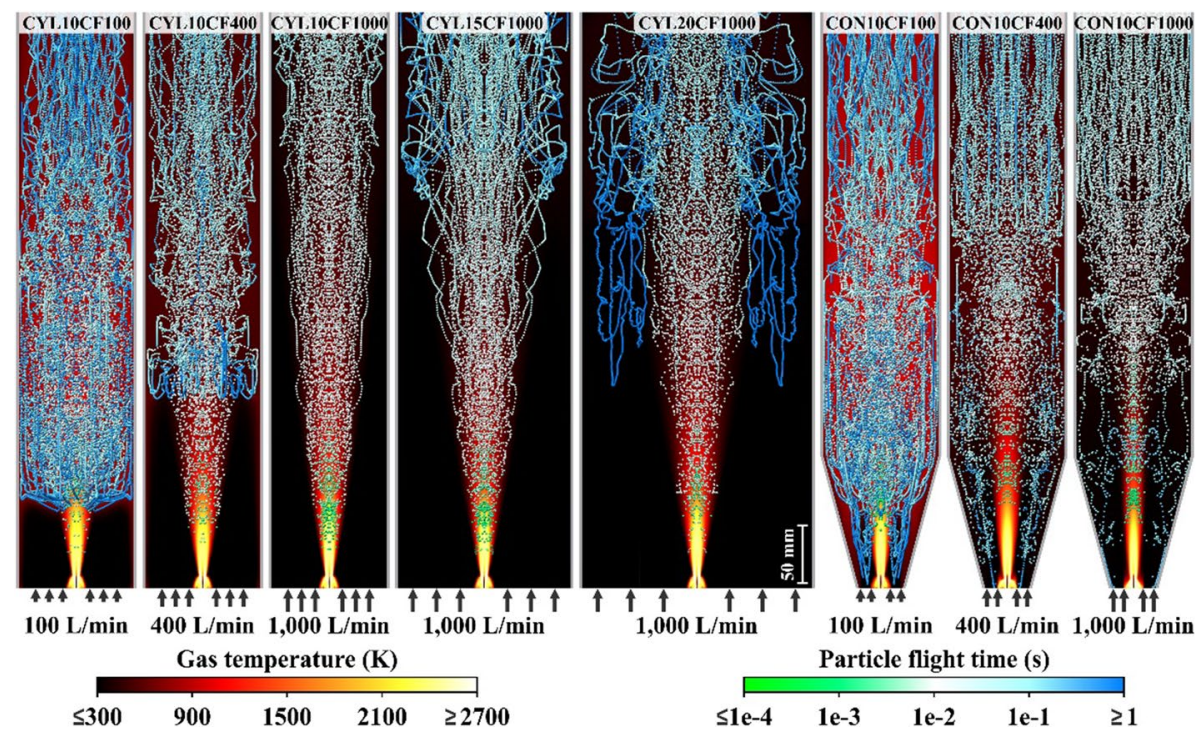

Fig. 8 Simulated gas temperature fields and particle trajectories (colored according to the flight time) with different reaction chamber geometries and co-flow rates 
In contrast, the cases with $100 \mathrm{~L} / \mathrm{min}$ present the largest TPRT and larger particle size is observed. For these cases (CYL10CF100 and CON10CF100) at $1000 \mathrm{~K}$, the TPRT is $\sim 0.14$ and $\sim 0.21$, respectively, $\mathrm{s}$ and reaches values smaller than $0.004 \mathrm{~s}$ in the regions with temperatures of $\sim 1500 \mathrm{~K}$ only. The results of the cases with co-flow rate $\geq 400 \mathrm{~L} /$ min are in the same order of magnitude $\left(\sim 8 \times 10^{-3} \mathrm{~s}\right.$ at $1000 \mathrm{~K}$ and $9 \times 10^{-4}-3 \times 10^{-3} \mathrm{~s}$ at $1500 \mathrm{~K}$ ) and are comparable to those presented by Gröhn et al. (2014), although the authors have applied a gas-to-liquid-mass-ratio, GLMR, of 1.8 (in this work, the GLMR is 1.7) with higher precursor and dispersion gas flow rates, and a single-step reaction mechanism in an open reactor configuration in their investigations.

As nanoparticle sintering is determined by the temperature history, primary particles with similar size are produced by the cases with 400 and $1000 \mathrm{~L} / \mathrm{min}$ co-flowing gas rates, as shown in Fig. 7. Decreasing the gas co-flow rate extends the TPRT due to the strong gas recirculation-since the particles follow the gas flow-and the lower amount of quenching gas provided.

The residence-time of particles into the reaction chamber also affects the agglomerate particle size. The lower is the residence-time, the smaller is the agglomerate diameter (Fig. 7).

These results highlight the impact of distinct operating conditions on the gas behavior inside the reactor, which directly influence the TPRT inside the hot zones of the reactor and, consequently, influence the powder characteristics.

\section{Conclusions}

The impact of operating conditions and geometric parameters on the flow behavior (gas and particles) in enclosed atmospheres produced by an FSP reactor has been highlighted. In the flame spray pyrolysis process, different co-flow rates were evaluated and its influence on the reactor temperature and flow behavior has been shown. Providing co-flow rates $\geq 400 \mathrm{~L} / \mathrm{min}$ to the cylindrical reaction chamber, almost no vortex formation and recirculation zones were observed inside the reactor. Although the co-flow rate provided to the conical reaction chamber is similar, recirculation zones were observed for all cases

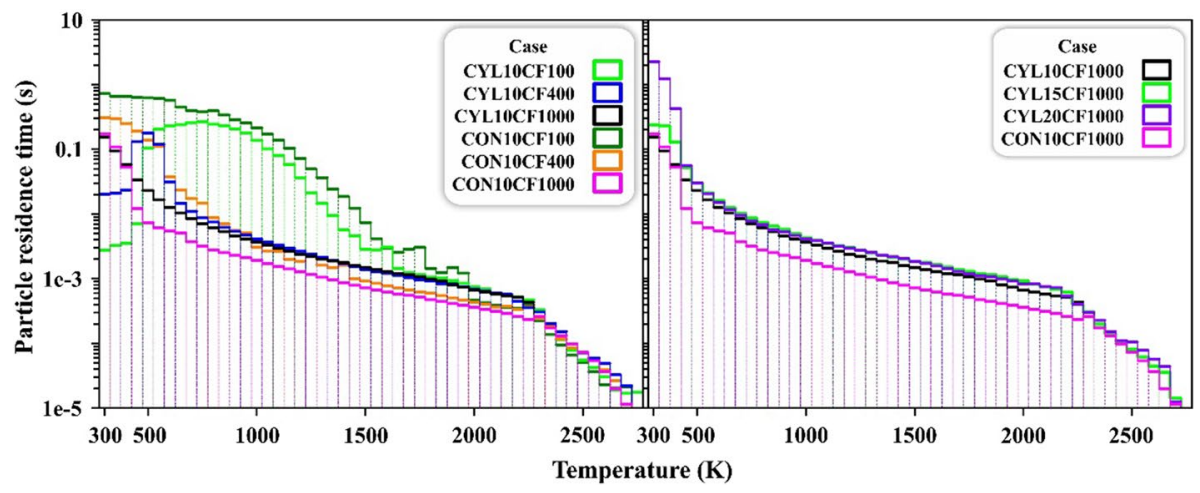

Fig. 9 Temperature-particle-residence-time (TPRT) of different operating conditions and reaction chamber geometries of the FSP process 
using the conical geometry. Additionally, reducing the co-flow rate provided to the cylindrical geometry, stronger vortex formation, hot gas recirculation, and higher temperature distributions have been observed, leading to larger TPRT distributions inside the flame or in the hot zones of the reactor. It was demonstrated that the TPRT is closely linked to the amount of co-flowing gas provided, since by reducing the rates of co-flowing gas the overall residence-time of nanoparticles increased considerably, especially inside the flame or in the hot areas. Thus, it can be deduced that manipulating the co-flowing gas rate it is possible to control the TPRT in the hot regions of the FSP reactor and, in turn, the structure and characteristics of the produced nanoparticles.

Particle losses to the reaction chamber walls due to the deposition processes is an interesting investigation point and the model can predict such losses. However, experimental data need to be taken to validate the model regarding particle losses/deposition on the reaction chamber walls.

Acknowledgments This contribution has received funding from the German Research Foundation-DFG (Project ID: FR 912/33), Coordination for the Improvement of Higher Education Personnel-CAPES (Process ID: BEX 12369/12-8), and São Paulo Research Foundation-FAPESP (Project ID: 2017/04045-0) in Brazil, and is part of the framework program Brazilian-German Collaborative Research Initiative on Manufacturing Technology (BRAGECRIM).

Funding Open Access funding enabled and organized by Projekt DEAL.

\section{Compliance with Ethical Standards}

Conflict of interest The authors declare that they have no Conflict of interest.

\section{Appendix 1: Basic Equations}

The mathematical formulation presented below remains with the transient terms for general convenience, although the assumption of the steady-state process is applied in numerical simulations.

See Tables 6, 7, 8, 9 and 10. 
Table 6 Eulerian governing equations

Eulerian governing equations

Continuity:

$$
\frac{\partial \rho}{\partial t}+\nabla \cdot(\rho \mathbf{v})=\sum a_{d} M_{d}
$$

Momentum conservation:

$$
\frac{\partial}{\partial t}(\rho \mathbf{v})+\nabla \cdot(\rho \mathbf{v v})=-\nabla p+\nabla \tau_{e f f}+\rho \mathbf{g}-\sum \rho_{d} F_{D}(\mathbf{v}-\mathbf{u})
$$

Energy conservation:

$$
\frac{\partial}{\partial t}(\rho h)+\nabla \cdot(\rho \mathbf{v} h)=\nabla \cdot\left(\lambda_{e f f} \nabla T\right)-\sum a_{d}\left[h_{\infty}\left(T-T_{d}\right)+h_{v a p} M_{d}\right]-\nabla \cdot \mathbf{q}_{r}-\sum_{r=1}^{r x n} h_{r, r x} R_{r}
$$

Chemical species conservation:

$$
\frac{\partial}{\partial t}\left(\rho Y_{i}\right)+\nabla \cdot\left(\rho \mathbf{v} Y_{i}\right)=-\nabla \cdot \mathbf{J}_{i, e f f}+\sum M_{d, i} \sum_{r=1}^{r x n} R_{i, r}
$$

Table 7 Lagrangian governing equations

\section{Lagrangian governing equations}

Force balance for a single droplet:

$$
m_{d} \frac{d \mathbf{u}}{d t}=m_{d} F_{D}(\mathbf{v}-\mathbf{u})+m_{d}\left(\frac{\rho_{d}-\rho}{\rho_{d}}\right) \mathbf{g}-\mathbf{u} \frac{d m_{d}}{d t}
$$

Energy equation:

$$
\frac{m_{d} C_{p}}{A_{d}} \frac{d T_{d}}{d t}=h_{\infty}\left(T-T_{d}\right)+\varepsilon_{d} \sigma\left(\theta_{R}^{4}-T_{d}^{4}\right)+h_{v a p} M_{d}
$$

Discrete random walk model (distributed random velocity fluctuation) (Gosman and Ioannides 1983):

$$
\mathbf{v}^{\prime}=\xi \sqrt{\frac{2 k}{3}}
$$

Parameters: Number of tries $=3$; time scale constant $=0.15$ 
Table 8 Closure equations
Closure equations

$k-\omega$ SST Turbulence Model (Menter 1994):

$\frac{\partial}{\partial t}(\rho k)+\nabla \cdot(\rho \mathbf{v} k)=\nabla \cdot\left(\Gamma_{k} \nabla_{k}\right)+G_{k}-D_{k}$

$\frac{\partial}{\partial t}(\rho \omega)+\nabla \cdot(\rho \mathbf{v} \omega)=\nabla \cdot\left(\Gamma_{\omega} \nabla_{\omega}\right)+G_{\omega}-D_{\omega}$

$\mathrm{P} 1$ radiation model (Howell et al. 2010):

$$
\begin{aligned}
& -\nabla \cdot \mathbf{q}_{r}=a G-4 a n^{2} \sigma T^{4} \\
& \nabla \cdot(\Psi \nabla G)-a G-4 a n^{2} \sigma T^{4}=0 \\
& \Psi=\frac{1}{\left[3\left(a+\sigma_{s}\right)-\sigma_{s}\right]}
\end{aligned}
$$

Drag force (Morsi and Alexander 1972):

$$
F_{D}=\frac{18 \mu}{\rho_{d} d_{d}^{2}} \frac{C_{D} R e}{24}
$$

Chemistry-turbulence interaction model (eddy dissipation concept model) (Ertesvåg and Magnussen 2000):

$$
R_{i, f s}=\frac{\rho \gamma^{*}}{\tau^{*}\left(1-\gamma^{* 1.5}\right)}\left(Y_{i}^{*}-Y_{i}\right)
$$

With

$$
\begin{aligned}
& \tau^{*}=0.4082\left(\frac{v}{\varepsilon}\right)^{\frac{1}{2}} \\
& \gamma^{*}=4.6\left(\frac{v \varepsilon}{k^{2}}\right)^{\frac{1}{2}} \\
& \sum_{r=1}^{n r x} R_{i, r}=R_{i, f s} \\
& \frac{d Y_{i}^{*}}{d t}=\sum_{r=1}^{n r x} \eta_{i, r}\left(A_{r} T^{\beta_{r}} e^{-E_{r} / R T} \prod_{j=1}^{n r a c}\left(Y_{j, r}^{*}\right)^{\alpha_{j, r}}\right) ; 0<t \leq \tau^{*}
\end{aligned}
$$


Table 9 Boundary conditions

Boundary conditions

Dispersion gas (mass-flow-inlet):

Momentum:

$$
\begin{aligned}
& \dot{m}_{\text {in }}=\dot{m}_{0} \\
& k_{\text {in }}=\frac{3}{2}(\overline{\mathrm{v}} l)^{2} \\
& \omega_{\text {in }}=\frac{k^{1 / 2}}{0.07 C_{\mu}^{1 / 4} D_{h}}
\end{aligned}
$$

Thermal:

$$
T_{\text {in }}=T_{0}
$$

Species:

$$
Y_{\mathrm{O}_{2} \text { in }}=Y_{\mathrm{O}_{2} 0}
$$

Pilot flame (mass-flow-inlet):

Momentum and thermal: same as in "dispersion gas"

Species:

$$
\begin{aligned}
& Y_{\mathrm{O}_{2 i n}}=Y_{\mathrm{O}_{2_{0}}} \\
& Y_{\mathrm{CH}_{4_{i n}}}=Y_{\mathrm{CH}_{4_{0}}}
\end{aligned}
$$

Porous plate (mass-flow-inlet):

Momentum and thermal: same as in "Dispersion gas"

Species:

$$
\begin{aligned}
& Y_{\mathrm{O}_{2_{i n}}}=Y_{\mathrm{O}_{2_{0}}} \\
& Y_{\mathrm{N}_{2_{i n}}}=Y_{\mathrm{N}_{2_{0}}}
\end{aligned}
$$

Nozzle walls and metallic plate (wall):

Momentum:

$$
\begin{aligned}
& \mathbf{v}=0 \\
& \left.\frac{\partial k}{\partial \zeta}\right|_{\text {wall }}=0
\end{aligned}
$$

A wall function was used in the near-wall regions

Thermal:

$$
\begin{aligned}
& \left.\frac{\partial T}{\partial \zeta}\right|_{\text {wall }}=0 \\
& q_{\text {in }}=0
\end{aligned}
$$

Species:

$$
Y_{i}=0
$$

Reactor walls (wall):

Momentum and Species: same as in Nozzle Walls

Thermal:

$q_{\text {in }}=-\left.k \frac{\partial T}{\partial \zeta}\right|_{\text {wall }}=U\left(T_{\text {wall }}-T_{\infty}\right)$ 
Table 9 (continued)

Boundary conditions

Outlet (pressure-outlet):

If inflow:

Momentum:

$$
\begin{aligned}
& \left.\frac{\partial \mathbf{v}}{\partial \zeta}\right|_{\text {out }}=0 \\
& \left.k\right|_{\text {out }}=k_{0} \\
& \left.\omega\right|_{\text {out }}=\omega_{0} \\
& p_{\text {static }}=p_{0}
\end{aligned}
$$

Thermal:

$$
T=T_{0}
$$

Species: same as in "porous plate"

If outflow:

Momentum:

$$
\begin{aligned}
& \left.\frac{\partial \mathbf{v}}{\partial \zeta}\right|_{\text {out }}=\left.\frac{\partial k}{\partial \zeta}\right|_{\text {out }}=\left.\frac{\partial \omega}{\partial \zeta}\right|_{\text {out }}=0 \\
& p_{\text {static }}=p_{0}
\end{aligned}
$$

Thermal:

$$
\left.\frac{\partial T}{\partial \zeta}\right|_{\text {out }}=0
$$

Species:

$$
\left.\frac{\partial Y_{i}}{\partial \zeta}\right|_{\text {out }}=0
$$

Axis (symmetry):

Momentum:

$$
\left.\frac{\partial \mathbf{v}}{\partial \zeta}\right|_{s y m}=\left.\frac{\partial k}{\partial \zeta}\right|_{s y m}=\left.\frac{\partial \omega}{\partial \zeta}\right|_{s y m}=0
$$

Thermal:

$$
\left.\frac{\partial T}{\partial \zeta}\right|_{\text {sym }}=0
$$

Species:

$$
\left.\frac{\partial Y_{i}}{\partial \zeta}\right|_{s y m}=0
$$

$\zeta$ is the orthogonal direction to the boundary; the standard wall functions available in ANSYS Fluent were applied 
Table 10 Population balance model
Population balance model

Number concentration conservation:

$$
\nabla \cdot(\rho \mathbf{v} N)-\nabla \cdot\left(\Gamma_{t} \nabla N\right)=k_{f}-\frac{1}{2} \beta(\rho N)^{2}
$$

Agglomerate surface area conservation:

$$
\nabla \cdot(\rho \mathbf{v} A)-\nabla \cdot\left(\Gamma_{t} \nabla A\right)=k_{f} a_{0}-\frac{\rho\left(A-N a_{s}\right)}{\tau_{s}}
$$

Agglomerate volume conservation:

$$
\nabla \cdot(\rho \mathbf{v} V)-\nabla \cdot\left(\Gamma_{t} \nabla V\right)=k_{f} v_{0}
$$

Nucleation rate:

$$
k_{f}=\frac{R_{o x} N a}{M_{o x}}
$$

Agglomeration rate:

$$
\beta=8 \pi D r_{c}\left[\frac{r_{c}}{2 r_{c}+\sqrt{2} g}+\frac{\sqrt{2} g}{c r_{c}}\right]^{-1}
$$

with

$$
\begin{aligned}
& D=\frac{k_{b} T}{6 \pi \mu r_{c}}\left[\frac{5+4 K n+6 K n^{2}+18 K n^{3}}{5-K n+(8+\pi) K n^{2}}\right] \\
& r_{c}=\frac{3 V}{A}\left(\frac{A^{3}}{36 \pi V^{2}}\right)^{\frac{1}{D_{f}}} \\
& c=\sqrt{\frac{8 k_{b} T}{\pi \rho_{p} V}} \\
& g=\frac{\left(2 r_{c}+\frac{8 D}{\pi c}\right)^{3}-\left[4 r_{c}^{2}+\left(\frac{8 D}{\pi c}\right)^{2}\right]^{\frac{3}{2}}}{6 r_{c} \frac{8 D}{\pi c}}
\end{aligned}
$$

Sintering time:

$$
\tau_{s}=0.001703 \frac{R T\left(\frac{d_{p}}{2}\right)^{4}}{w_{s} D_{b} \gamma \Omega}
$$

with

$$
D_{b}=3.5 \times 10^{-10} \exp \left(\frac{-1.88 \times 10^{5}}{R T}\right)
$$

\section{Appendix 2: Thermodynamic and Physical Properties of Liquid and Gaseous/Vapor Materials}

See Tables 11, 12, 13, 14, 15, 16 and 17. 
Table 11 Physical properties of liquid species used in the CFD setup

\begin{tabular}{llll}
\hline Property (unit) & Ethanol & n-propanol & $\begin{array}{l}\text { Zirco- } \\
\text { nium (IV) } \\
\text { n-propoxide }\end{array}$ \\
\hline Molar mass $\left(\mathrm{g} \mathrm{mol}^{-1}\right)$ & 46.068 & 60.095 & 327.572 \\
Melting temperature, $\mathrm{T}_{\mathrm{m}}(\mathrm{K})$ & $159.05^{\mathrm{a}}$ & $147^{\mathrm{a}}$ & $278.6^{\mathrm{b}}$ \\
Boiling temperature, $\mathrm{T}_{\mathrm{b}}(\mathrm{K})$ & $351.8^{\mathrm{a}}$ & $370.93^{\mathrm{a}}$ & $539.83^{\mathrm{b}}$ \\
Density, $\rho\left(\mathrm{kg} \mathrm{m}^{-3}\right)$ & 789.3 & 803.58 & 1044 \\
Latent heat of vaporization $\left(\mathrm{J} \mathrm{kg}^{-1}\right)$ & $833,305^{\mathrm{c}}$ & $688,572^{\mathrm{c}}$ & $253,651^{\mathrm{d}}$ \\
\hline
\end{tabular}

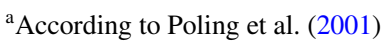

${ }^{\mathrm{b}}$ Estimated according to the Group-Contribution method presented by Constantinou and Gani (1994)

${ }^{\mathrm{c}}$ Estimated according to Coker (2010) at $\mathrm{T}_{\mathrm{b}}$

${ }^{\mathrm{d}}$ Estimated according to the Group-Contribution method presented by Constantinou and Gani (1994) at $\mathrm{T}_{\mathrm{b}}$

Table 12 Temperature-dependent parameters for a piecewise-polynomial function to estimate the heat capacity, $\mathrm{C}_{\mathrm{p}}$, of the liquid species used in the CFD setup

\begin{tabular}{|c|c|c|c|c|c|c|}
\hline \multirow[t]{2}{*}{ Substance } & \multicolumn{4}{|c|}{$C_{p}(T)=\sum_{i=0}^{n} A_{i} T^{i},\left(\mathrm{~J} \mathrm{~kg}^{-1} \mathrm{~K}^{-1}\right)$} & \multirow[t]{2}{*}{$\mathrm{T}_{\min }(\mathrm{K})$} & \multirow[t]{2}{*}{$\mathrm{T}_{\max }(\mathrm{K})$} \\
\hline & $\overline{\mathrm{A}_{0}}$ & $\mathrm{~A}_{1}$ & $\mathrm{~A}_{2}$ & $\mathrm{~A}_{3}$ & & \\
\hline Ethanol $^{\mathrm{a}}$ & 1288.1270 & 7.8922 & $-2.6404 \mathrm{E}-02$ & $3.9137 \mathrm{E}-05$ & 159.05 & 513.92 \\
\hline$n$-propanol ${ }^{\mathrm{a}}$ & 1465.6796 & 6.6934 & $-2.1686 \mathrm{E}-02$ & $3.2743 \mathrm{E}-05$ & 147 & 536.78 \\
\hline $\begin{array}{l}\text { Zirconium (IV) } \\
\text { n-propoxide }\end{array}$ & 1199.5214 & $4.1457 \mathrm{E}-01$ & $3.0497 \mathrm{E}-03$ & & 278.6 & 706.38 \\
\hline
\end{tabular}

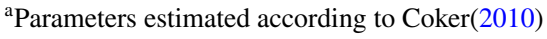

${ }^{\mathrm{b}}$ Parameters estimated according to the Group-Contribution method presented by Kolská et al. (2008) 
Table 13 Saturation vapor pressure of liquid species used in the CFD setup

\begin{tabular}{|c|c|c|c|}
\hline \multirow[t]{2}{*}{ Temperature (K) } & \multicolumn{3}{|c|}{ Saturation Vapor Pressure $(\mathrm{Pa})$} \\
\hline & Ethanol $^{\mathrm{a}}$ & $n$-propanol ${ }^{\mathrm{b}}$ & $\begin{array}{l}\text { Zirconium (IV) } \\
n \text {-propoxide }\end{array}$ \\
\hline 271 & 1329 & 388 & \\
\hline $278.6^{\mathrm{d}}$ & 2338 & 703 & 0.18 \\
\hline 281 & 2658 & 842 & 0.23 \\
\hline 292 & 5316 & 1837 & 0.75 \\
\hline 299 & 7974 & 2914 & 1.49 \\
\hline 308 & 13,289 & 5083 & 3.40 \\
\hline 321 & 26,579 & 10,633 & 10.2 \\
\hline 337 & 53,158 & 24,011 & 33.9 \\
\hline 351 & 101,000 & 45,481 & 87.1 \\
\hline 370 & 202,000 & 98,431 & 271.6 \\
\hline 399 & 505,000 & 268,266 & 1189 \\
\hline 422 & $1,000,000$ & 524,958 & 3201 \\
\hline 455 & $2,000,000$ & $1,180,390$ & 10,642 \\
\hline 500 & $5,000,000$ & $2,839,715$ & 39,824 \\
\hline $513.92^{\mathrm{e}}$ & $6,148,000$ & $3,569,967$ & 56,496 \\
\hline $536.78^{\mathrm{f}}$ & & $5,012,639$ & 95,558 \\
\hline 575 & & & 205,508 \\
\hline 600 & & & 318,743 \\
\hline 625 & & & 475,354 \\
\hline 650 & & & 686,602 \\
\hline 675 & & & 967,224 \\
\hline $706.38^{\mathrm{g}}$ & & & $1,454,822$ \\
\hline
\end{tabular}

Property data for piecewise-linear functions

$\left(\phi(\mathrm{T})=\phi_{n}+\frac{\phi_{n+1}-\phi_{n}}{T_{n+1}-T_{n}}\left(T-T_{n}\right)\right)$

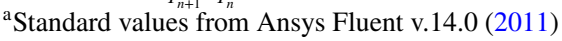

${ }^{b}$ Estimated according to data from Coker (2010)

${ }^{c}$ Estimated according to Ambrose-Walton Corresponding-State Method (Poling et al. 2001)

${ }^{\mathrm{d}}$ Melting temperature, $\mathrm{T}_{\mathrm{m}}$, of zirconium (IV) $n$-propoxide, estimated according to the Group-Contribution method presented by Constantinou and Gani 1994

${ }^{\mathrm{e}} \mathrm{Critical}$ temperature, $\mathrm{T}_{\mathrm{c}}$, of ethanol (Poling et al. 2001)

${ }^{\mathrm{f}}$ Critical temperature, $\mathrm{T}_{\mathrm{c}}$, of $n$-propanol (Poling et al. 2001)

${ }^{g}$ Critical temperature, $T_{c}$, of zirconium (IV) $n$-propoxide, estimated according to the Group-Contribution method presented by Constantinou and Gani (1994) 


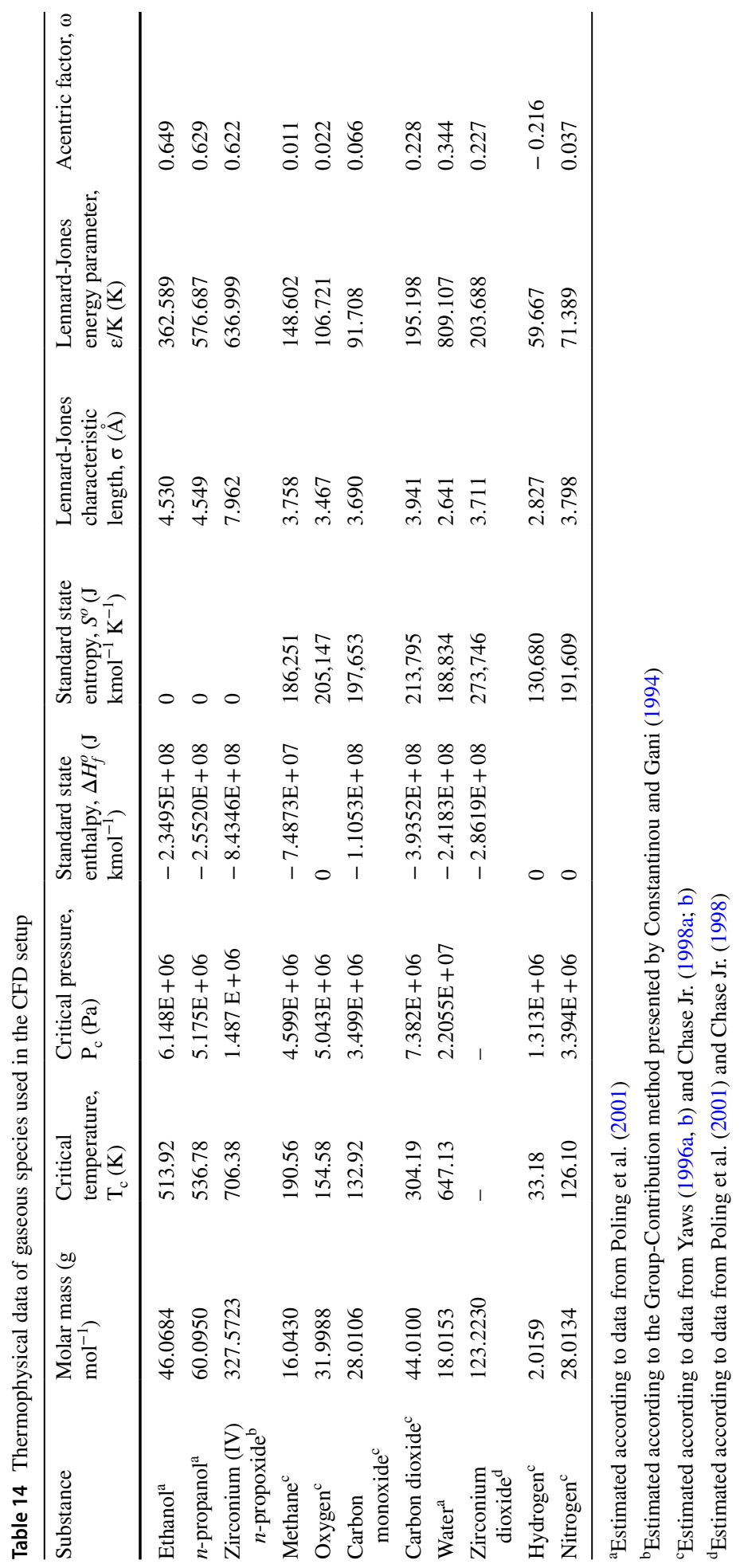




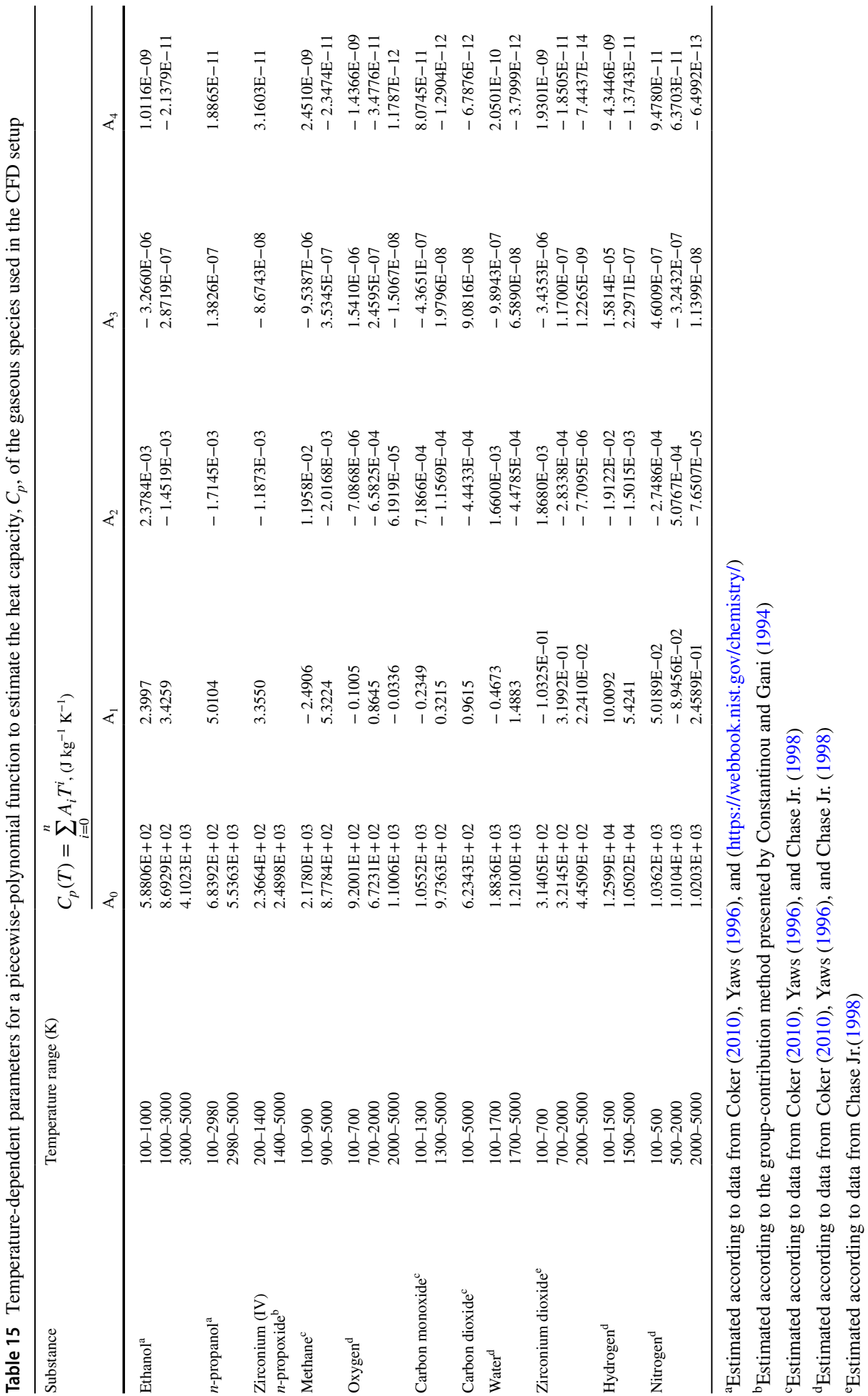


Table 16 Temperature-dependent parameters for a piecewise-polynomial function to estimate the thermal conductivity, $k_{g a s}$, of the gaseous species used in the CFD setup

\begin{tabular}{|c|c|c|c|c|c|}
\hline \multirow[t]{2}{*}{ Substance } & \multirow[t]{2}{*}{$\begin{array}{l}\text { Temperature range } \\
(\mathrm{K})\end{array}$} & \multicolumn{4}{|c|}{$k_{\text {gas }}(T)=\sum_{i=0}^{n} A_{i} T^{i},\left(\mathrm{~W} \mathrm{~m}^{-1} \mathrm{~K}^{-1}\right)$} \\
\hline & & $\overline{\mathrm{A}_{0}}$ & $\mathrm{~A}_{1}$ & $\mathrm{~A}_{2}$ & $\mathrm{~A}_{3}$ \\
\hline Ethanol $^{\mathrm{a}}$ & $\begin{array}{l}250-1500 \\
1500-5000\end{array}$ & $\begin{array}{l}-1.3405 \mathrm{E}-02 \\
0.170003\end{array}$ & $7.0239 \mathrm{E}-05$ & $9.0124 \mathrm{E}-08$ & $-3.6957 \mathrm{E}-11$ \\
\hline$n$-propanol ${ }^{\mathrm{a}}$ & $\begin{array}{l}250-1500 \\
1500-5000\end{array}$ & $\begin{array}{l}-8.9276 \mathrm{E}-04 \\
0.147767\end{array}$ & $2.7035 \mathrm{E}-05$ & $1.0258 \mathrm{E}-07$ & $-3.6355 E-11$ \\
\hline $\begin{array}{l}\text { Zirconium (IV) } \\
n \text {-propoxide }\end{array}$ & $100-5000$ & 0.0062 & & & \\
\hline Methane $^{a}$ & $\begin{array}{l}97-1500 \\
1500-5000\end{array}$ & $\begin{array}{l}5.3767 \mathrm{E}-03 \\
0.264505\end{array}$ & $5.1555 \mathrm{E}-05$ & $1.6655 \mathrm{E}-07$ & $-5.7168 \mathrm{E}-11$ \\
\hline Oxygen $^{a}$ & $\begin{array}{l}80-2000 \\
2000-5000\end{array}$ & $\begin{array}{l}1.5475 \mathrm{E}-04 \\
0.120000\end{array}$ & $9.4153 \mathrm{E}-05$ & $-2.7529 \mathrm{E}-08$ & $5.2069 \mathrm{E}-12$ \\
\hline Carbon monoxide ${ }^{a}$ & $\begin{array}{l}70-1500 \\
1500-5000\end{array}$ & $\begin{array}{l}9.9186 \mathrm{E}-04 \\
0.096719\end{array}$ & $9.4020 \mathrm{E}-05$ & $-4.0761 \mathrm{E}-08$ & $-2.2403 \mathrm{E}-08$ \\
\hline Carbon dioxide $^{\mathrm{a}}$ & $\begin{array}{l}195-1500 \\
1500-5000\end{array}$ & $\begin{array}{l}-0.01200 \\
0.090713\end{array}$ & $1.0208 \mathrm{E}-04$ & $-2.2403 E-08$ & \\
\hline Water $^{\mathrm{a}}$ & $\begin{array}{l}150-1500 \\
1500-5000\end{array}$ & $\begin{array}{l}5.6199 \mathrm{E}-03 \\
0.174602\end{array}$ & $1.5699 \mathrm{E}-05$ & $1.0106 \mathrm{E}-07$ & $-2.4282 E-11$ \\
\hline Zirconium dioxide $^{\mathrm{a}}$ & $100-5000$ & 0.0062 & & & \\
\hline Hydrogen $^{\mathrm{a}}$ & $\begin{array}{l}15-1500 \\
1500-5000\end{array}$ & $\begin{array}{l}1.0979 \mathrm{E}-02 \\
0.561969\end{array}$ & $6.6411 \mathrm{E}-04$ & $-3.4378 \mathrm{E}-07$ & $9.7283 \mathrm{E}-11$ \\
\hline Nitrogen $^{a}$ & $\begin{array}{l}78-1500 \\
1500-5000\end{array}$ & $\begin{array}{l}-2.2678 \mathrm{E}-04 \\
0.093929\end{array}$ & $1.0275 \mathrm{E}-04$ & $-6.0151 \mathrm{E}-08$ & $2.2332 \mathrm{E}-11$ \\
\hline
\end{tabular}

${ }^{\mathrm{a}}$ Estimated according to data from Coker (2010) and Yaws (2015)

${ }^{\mathrm{b}}$ Constant value according to Gröhn et al. (2012) 
Table 17 Temperature-dependent parameters for a piecewise-polynomial function to estimate the dynamic viscosity, $\mu_{\text {gas }}$, of the gaseous species used in the CFD setup

\begin{tabular}{|c|c|c|c|c|c|}
\hline \multirow[t]{2}{*}{ Substance } & \multirow[t]{2}{*}{$\begin{array}{l}\text { Temperature range } \\
(\mathrm{K})\end{array}$} & \multicolumn{4}{|c|}{$\mu_{\text {gas }}(T)=\sum_{i=0}^{n} A_{i} T^{i},\left(\mathrm{~kg} \mathrm{~m}^{-1} \mathrm{~s}^{-1}\right)$} \\
\hline & & $\overline{\mathrm{A}_{0}}$ & $\mathrm{~A}_{1}$ & $\mathrm{~A}_{2}$ & $\mathrm{~A}_{3}$ \\
\hline Ethanol $^{\mathrm{a}}$ & $\begin{array}{l}200-1500 \\
1500-5000\end{array}$ & $\begin{array}{l}1.8086 \mathrm{E}-07 \\
3.6103 \mathrm{E}-05\end{array}$ & $3.0504 \mathrm{E}-08$ & $-3.9837 \mathrm{E}-12$ & $-2.5788 \mathrm{E}-16$ \\
\hline$n$-propanol ${ }^{\mathrm{a}}$ & $\begin{array}{l}200-1500 \\
1500-5000\end{array}$ & $\begin{array}{l}-1.5607 \mathrm{E}-06 \\
3.4060 \mathrm{E}-05\end{array}$ & $3.2718 \mathrm{E}-08$ & $-6.8721 \mathrm{E}-12$ & $5.9445 \mathrm{E}-16$ \\
\hline $\begin{array}{c}\text { Zirconium (IV) } \\
n \text {-propoxide }\end{array}$ & $100-5000$ & $5.4400 \mathrm{E}-06$ & & & \\
\hline Methane $^{\mathrm{a}}$ & $\begin{array}{l}91-1500 \\
1500-5000\end{array}$ & $\begin{array}{l}1.2603 \mathrm{E}-07 \\
3.5064 \mathrm{E}-05\end{array}$ & $4.3804 \mathrm{E}-08$ & $-2.4322 \mathrm{E}-11$ & $7.0981 \mathrm{E}-15$ \\
\hline Oxygen $^{\mathrm{a}}$ & $\begin{array}{l}54-1500 \\
1500-5000\end{array}$ & $\begin{array}{l}-4.9433 \mathrm{E}-07 \\
6.3704 \mathrm{E}-05\end{array}$ & $8.0673 \mathrm{E}-08$ & $-4.0416 \mathrm{E}-11$ & $1.0111 \mathrm{E}-14$ \\
\hline Carbon monoxide ${ }^{\mathrm{a}}$ & $\begin{array}{l}68-1500 \\
1500-5000\end{array}$ & $\begin{array}{l}1.8049 \mathrm{E}-06 \\
5.1720 \mathrm{E}-05\end{array}$ & $6.3753 \mathrm{E}-08$ & $-3.5748 \mathrm{E}-11$ & $1.0287 \mathrm{E}-14$ \\
\hline Carbon dioxide $^{\mathrm{a}}$ & $\begin{array}{l}195-1500 \\
1500-5000\end{array}$ & $\begin{array}{l}1.1811 \mathrm{E}-06 \\
5.1523 \mathrm{E}-05\end{array}$ & $4.9838 \mathrm{E}-08$ & $-1.0851 \mathrm{E}-11$ & \\
\hline Water $^{\mathrm{a}}$ & $\begin{array}{l}150-1500 \\
1500-5000\end{array}$ & $\begin{array}{l}2.2821 \mathrm{E}-06 \\
5.3032 \mathrm{E}-05\end{array}$ & $1.7387 \mathrm{E}-08$ & $3.2465 \mathrm{E}-11$ & $-1.4334 \mathrm{E}-14$ \\
\hline Zirconium dioxide $^{\mathrm{b}}$ & $100-5000$ & $5.4400 \mathrm{E}-06$ & & & \\
\hline Hydrogen $^{a}$ & $\begin{array}{l}15-1500 \\
1500-5000\end{array}$ & $\begin{array}{l}1.7611 \mathrm{E}-07 \\
2.7358 \mathrm{E}-05\end{array}$ & $3.4165 \mathrm{E}-08$ & $-1.8368 \mathrm{E}-11$ & $5.1147 \mathrm{E}-15$ \\
\hline Nitrogen $^{\mathrm{a}}$ & $\begin{array}{l}63-1970 \\
1970-5000\end{array}$ & $\begin{array}{l}4.4656 \mathrm{E}-07 \\
6.4315 \mathrm{E}-05\end{array}$ & $6.3814 \mathrm{E}-08$ & $-2.6596 \mathrm{E}-11$ & $5.4113 \mathrm{E}-15$ \\
\hline
\end{tabular}

${ }^{\mathrm{a}}$ Estimated according to data from Coker (2010) and Yaws (2015)

${ }^{\mathrm{b}}$ Constant value according to Gröhn et al. (2012)

Open Access This article is licensed under a Creative Commons Attribution 4.0 International License, which permits use, sharing, adaptation, distribution and reproduction in any medium or format, as long as you give appropriate credit to the original author(s) and the source, provide a link to the Creative Commons licence, and indicate if changes were made. The images or other third party material in this article are included in the article's Creative Commons licence, unless indicated otherwise in a credit line to the material. If material is not included in the article's Creative Commons licence and your intended use is not permitted by statutory regulation or exceeds the permitted use, you will need to obtain permission directly from the copyright holder. To view a copy of this licence, visit http://creativecommons.org/licenses/by/4.0/.

\section{References}

Achelis, L., Meierhofer, F., Hodapp, M.J., Buss, L., Noriler, D., Meier, H.F., Fritsching, U.: Novel atomization process for large scale nanoparticle production by flame spray pyrolysis. In: Proceedings of the ASME 2014: 4th Joint US-European Fluids Engineering Division Summer Meeting (2014)

Andersen, J., Rasmussen, C.L., Giselsson, T., Glarborg, P.: Global combustion mechanisms for use in CFD modeling under oxy-fuel conditions. Energ. Fuel. 23, 1379-1389 (2009)

Ansys: Ansys Fluent 14.0 Theory Guide. ANSYS, Inc., USA (2011)

Batchelor, G.K., Shen, C.: Thermophoretic deposition of particles in gas flowing over cold surfaces. J. Colloid Interf. Sci. 107(1), 21-37 (1985) 
Bianchi Neto, P., Buss, L., Meierhofer, F., Meier, H.F., Fritsching, U., Noriler, D.: Combustion kinetic analysis of flame spray pyrolysis process. Chem. Eng. Process. 129, 17-27 (2018)

Brockmann, J.E.: Aerosol transport in sampling lines and inlets. In: Kulkarni, P., Baron, P.A., Willeke, K. (eds.) Aerosol Measurements: Principles, Techniques, and Applications. Wiley, Hoboken (2011)

Brossmann, U., Würschum, R., Södervall, U., Schaefer, H.E.: Oxygen diffusion in ultrafine grained monoclinic $\mathrm{ZrO}_{2}$. J. Appl. Phys. 85(11), 7646-7654 (1999)

Buesser, B., Gröhn, A.J.: Multiscale aspects of modeling gas-phase nanoparticle synthesis. Chem. Eng. Technol. 35(7), 1133-1143 (2012)

Buss, L., Meierhofer, F., Noriler, D., Meier, H.F., Fritsching, U.: Influence of air entrainment on the flame spray process. In: ILASS: Europe 2016, 27th Annual Conference on Liquid Atomization and Spray Systems (2016)

Buss, L., Bianchi Neto, P., França Meier, H., Noriler, D., Fritsching, U.: Temperature distribution in open and enclosed flame spray reactor. In: ICLASS 2018: 14th Triennial International Conference on Liquid Atomization and Spray Systems (2018)

Buss, L., Meierhofer, F., Bianchi Neto, P., Meier, H.F., Fritsching, U., Noriler, D.: Impact of co-flow on the spray flame behaviour applied to nanoparticle synthesis. Can. J. Chem. Eng. 97, 604-615 (2019)

Celik, I.B., Ghia, U., Roache, P.J., Freitas, C.J., Coleman, H., Raad, P.E.: Procedure for estimation and reporting of uncertainty due to discretization in CFD applications. J. Fluids Eng. 130(7), 07800110780014 (2008)

Chase Jr., M.W.: NIST-JANAF Thermochemical Tables: Part I, Al-Co, 4th edn. National Institute of Standards and Technology, Gaithersburg (1998a)

Chase Jr., M.W.: NIST-JANAF Thermochemical Tables: Part II, Cr-Zr, 4th edn. National Institute of Standards and Technology, Gaithersburg (1998b)

Coblenz, W.S., Dynys, J.M., Cannon, R.M., Coble, R.L.: Initial stage solid state sintering models: a critical analysis and assessment. In: Kuczynski, G.C. (ed.) Sintering Processes: Material Science Research, pp. 141-157. Plenum, New York (1980)

Coker, A.K.: Physical properties of liquids and gases. In: Ludwig's Applied Process Design for Chemical and Petrochemical Plants, pp. 757-792. Elsevier Inc., Burlington, USA (2010)

Constantinou, L., Gani, R.: New group contribution method for estimating properties of pure compounds. AIChE J. 40(10), 1697-1710 (1994)

Curtet, R.: Confined jets and recirculation phenomena with cold air. Combust. Flame 2(4), 383-411 (1958)

Ertesvåg, I.S., Magnussen, B.F.: The eddy dissipation turbulence energy cascade. Combust. Sci. Technol. 159, 213-235 (2000)

Fritsching, U.: Spray systems. In: Crowe, C.T. (ed.) Multiphase Flow Handbook, pp. 8-1-8-100. CRC Press, Boca Raton (2006)

Gosman, A.D., Ioannides, E.: Aspects of computer simulation of liquid-fueled combustors. J. Energy 7(6), 482-490 (1983)

Gröhn, A.J., Pratsinis, S.E., Wegner, K.: Fluid-particle dynamics during combustion spray aerosol synthesis of $\mathrm{ZrO}_{2}$. Chem. Eng. J. 191, 491-502 (2012)

Gröhn, A.J., Pratsinis, S.E., Sánchez-Ferrer, A., Mezzenga, R., Wegner, K.: Scale-up of nanoparticle synthesis by flame spray pyrolysis: the high-temperature particle residence time. Ind. Eng. Chem. Res. 53, 10734-10742 (2014)

Grossmann, H.K., Grieb, T., Meierhofer, F., Hodapp, M.J., Noriler, D., Gröhn, A., Meier, H.F., Fritsching, U., Wegner, K., Mädler, L.: Nanoscale mixing during double-flame spray synthesis of heterostructured nanoparticles. J. Nanopart. Res. 17(4), 174 (2015)

Hill, C.G., Root, T.W.: Introduction to Chemical Engineering Kinetics and Reactor Design, 2nd edn. Wiley, Hoboken (2014)

Howell, J.R., Mengüç, M.P., Siegel, R.: Thermal Radiation Heat Transfer, 5th edn. CRC Press, Boca Raton (2010)

Jones, W.P., Lindstedt, R.P.: Global reaction schemes for hydrocarbon combustion. Combust. Flame 73(3), 233-249 (1988)

Kho, Y.K., Teoh, W.Y., Mädler, L., Amal, R.: Dopant-free, polymorphic design of $\mathrm{TiO}_{2}$ nanocrystals by flame aerosol synthesis. Chem. Eng. Sci. 66, 2409-2416 (2011)

Kim, I., Schiller, D.N., Sirignano, W.A.: Axisymmetric flame spread across propanol pools in normal and zero gravity. Combust. Sci. Technol. 139(1), 249-275 (1998)

Kolská, Z., Kukal, J., Zábranský, M., Růžička, V.: Estimation of the heat capacity of organic liquids as a function of temperature by a three-level group contribution method. Ind. Eng. Chem. Res. 47(6), 2075-2085 (2008) 
Kruis, F.E., Kuster, K.A., Pratsinis, S.E., Scarlett, B.: A simple-model for the evolution of the characteristics of aggregate particles undergoing coagulation and sintering. Aerosol Sci. Technol. 19(4), 514-526 (1993)

Li, D., Teoh, W.Y., Selomulya, C., Woodward, R.C., Munroe, P., Amal, R.: Insight into microstructural and magnetic properties of flame-made $\gamma-\mathrm{Fe}_{2} \mathrm{O}_{3}$ nanoparticles. J. Mater. Chem. 17, 4876-4884 (2007)

Mädler, L., Kammler, H.K., Mueller, R., Pratsinis, S.E.: Controlled synthesis of nanostructured particles by flame spray pyrolysis. J. Aerosol Sci. 33, 369-389 (2002)

Mädler, L., Roessler, A., Pratsinis, S.E., Sahm, T., Gurlo, A., Barsan, N., Weimar, U.: Direct formation of highly porous gas-sensing films by in situ thermophoretic deposition of flame-made $\mathrm{Pt} / \mathrm{SnO}_{2}$ nanoparticles. Sens. Actuators B 114(1), 283-295 (2006)

Magnussen, B.F.: Prediction of characteristics of enclosed turbulent jet flames. Symp. Int. Combust. 14(1), 553-565 (1973)

Meierhofer, F., Hodapp, M.J., Achelis, L., Buss, L., Noriler, D., Meier, H.F., Fritsching, U.: Investigation of atomization concepts for large-scale flame spray pyrolysis (FSP). Materialwiss. Werkstofftech. 45(8), 765-778 (2014)

Meierhofer, F., Buss, L., Noriler, D., Meier, H.F., Fritsching, U.: The influence of reactor enclosure and gas entrainment on flame sprays with application in nanoparticle synthesis. In: ICMF 2016: 9th International Conference on Multiphase Flow (2016)

Meierhofer, F., Li, H., Gockeln, M., Kun, R., Grieb, T., Rosenauer, A., Fritsching, U., Kiefer, J., Birkenstock, J., Mädler, L., Pokhrel, S.: Screening Precursor-Solvent Combinations for $\mathrm{Li}_{4} \mathrm{Ti}_{5} \mathrm{O}_{12}$ Energy Storage Material Using Flame Spray Pyrolysis. ACS Appl. Mater. Interfaces. 9, 37760-37777 (2017)

Menter, F.R.: Two-equation eddy-viscosity turbulence models for engineering applications. AIAA J. 32(8), 1598-1605 (1994)

Morsi, S.A., Alexander, A.J.: An investigation of particle trajectories in two-phase flow systems. J. Fluid Mech. 55(2), 193-208 (1972)

Mueller, R., Jossen, R., Pratsinis, S.E., Watson, M., Akhtar, M.K.: Zirconia nanoparticles made in spray flames at high production rates. J. Am. Ceram. Soc. 87(2), 197-202 (2004)

NIST Standard Reference Database Number 69. In: NIST Chemistry WebBook. https://webbook.nist.gov/ chemistry/

Oldenhof, E., Tummers, M.J., van Veen, E.H., Roekaerts, D.J.E.M.: Role of entrainment in the stabilisation of jet-in-hot-coflow flames. Combust. Flame 158(8), 1553-1563 (2011)

Pettibone, J.M., Elzey, S., Grassian, V.H.: An integrated approach toward understanding the environmental fate, transport, toxicity, and health hazards of nanomaterials. In: Grassian, V.H. (ed.) Nanoscience and Nanotechnology: Environmental and Health Impacts. Wiley, Hoboken (2008)

Poling, B.E., Prausnitz, J.M., O'Connell, J.P.: The Properties of Gases and Liquids, 5th edn. McGraw-Hill Education, New York (2001)

Pratsinis, S.E.: Aerosol-based technologies in nanoscale manufacturing: from functional materials to devices through core chemical engineering. AIChE J. 56, 3028-3035 (2010)

Ricou, F.P., Spalding, D.B.: Measurements of entrainment by axisymmetrical turbulent jets. J. Fluid Mech. 11(1), 21-32 (1961)

Romay, F.J., Takagaki, S.S., Pui, D.Y.H., Liu, B.Y.H.: Thermophoretic deposition of aerosol particles in turbulent pipe flow. J. Aerosol Sci. 29(8), 943-959 (1998)

Stodt, M.F.B., Kiefer, J., Fritsching, U.: Ethanol droplet formation, dynamics and combustion mode in the flame of the SpraySyn-nozzle. Exp. Fluids 60(8), 125 (2019)

Talbot, L., Cheng, R.K., Schefer, R.W., Willis, D.R.: Thermophoresis of particles in a heated boundary layer. J. Fluid Mech. 101(4), 737-758 (1980)

Teoh, W.Y., Amal, R., Mädler, L.: Flame spray pyrolysis: an enabling technology for nanoparticles design and fabrication. Nanoscale 2(8), 1324-1347 (2010)

Waser, O., Hess, M., Güntner, A., Novák, P., Pratsinis, S.E.: Size controlled CuO nanoparticles for Li-ion batteries. J. Power Sources 241, 415-422 (2013)

Waser, O., Brenner, O., Groehn, A.J., Pratsinis, S.E.: Process design for size-controlled flame spray synthesis of $\mathrm{Li}_{4} \mathrm{Ti}_{5} \mathrm{O}_{12}$ and electrochemical performance. Chem. Process Eng. 38(1), 51-66 (2017)

Westbrook, C.K., Dryer, F.L.: Simplified reaction mechanisms for oxidation of hydrocarbon fuels in flames. Combust. Sci. Technol. 27(1-2), 31-43 (1981)

Yaws, C.L.: Handbook of Thermodynamic Diagrams: C1 to C4 Compounds 1. Gulf Publishing Company, Houston (1996a)

Yaws, C.L.: Handbook of Thermodynamic Diagrams: Inorganic Compounds and Elements 4. Gulf Publishing Company, Houston (1996b)

Yaws, C.L.: Transport Properties of Chemicals and Hydrocarbons, 2nd edn. Gulf Professional Publishing, Waltham, USA (2015) 